\title{
Contribution of oceanic and vegetation feedbacks to Holocene climate change in monsoonal Asia
}

\author{
A. Dallmeyer ${ }^{1}$, M. Claussen ${ }^{1,2}$, and J. Otto ${ }^{1,3}$ \\ ${ }^{1}$ Max Planck Institute for Meteorology, Hamburg, Germany \\ ${ }^{2}$ Meteorological Institute, KlimaCampus, University Hamburg, Germany \\ ${ }^{3}$ International Max-Planck-Research School, Hamburg, Germany \\ Received: 23 September 2009 - Published in Clim. Past Discuss.: 21 October 2009 \\ Revised: 10 February 2010 - Accepted: 18 March 2010 - Published: 7 April 2010
}

\begin{abstract}
The impact of vegetation-atmosphere and ocean-atmosphere interactions on the mid- to late Holocene climate change as well as their synergy is studied for different parts of the Asian monsoon region, giving consideration to the large climatic and topographical heterogeneity in that area. We concentrate on temperature and precipitation changes as the main parameters describing monsoonal influenced climates. For our purpose, we analyse a set of coupled numerical experiments, performed with the comprehensive Earth system model ECHAM5/JSBACH-MPIOM under present-day and mid-Holocene (6k) orbital configurations (Otto et al., $2009 \mathrm{~b}$ ). The temperature change caused by the insolation forcing reveals an enhanced seasonal cycle, with a pronounced warming in summer $(0.58 \mathrm{~K})$ and autumn $(1.29 \mathrm{~K})$ and a cooling in the other seasons (spring: $-1.32 \mathrm{~K}$; winter: $-0.97 \mathrm{~K})$. Most of this change can be attributed to the direct response of the atmosphere, but the ocean, whose reaction has a lagged seasonal cycle (warming in autumn and winter, cooling in the other seasons), strongly modifies the signal. The simulated contribution of dynamic vegetation is small and most effective in winter, where it slightly warms the near-surface atmosphere (approx. $0.03 \mathrm{~K}$ ). The temperature difference attributed to the synergy is on average positive, but also small. Concerning the precipitation, the most remarkable change is the postponement and enhancement of the Asian monsoon $(0.46 \mathrm{~mm} /$ day in summer, $0.53 \mathrm{~mm} /$ day in autumn $)$, mainly related to the direct atmospheric response. On regional average, the interactive ocean (ca. $0.18 \mathrm{~mm} /$ day) amplifies
\end{abstract}

Correspondence to: A. Dallmeyer

(anne.dallmeyer@zmaw.de) the direct effect, but tends to weaken the East Asian summer monsoon and strongly increases the Indian summer monsoon rainfall rate $(0.68 \mathrm{~mm} /$ day $)$. The influence of dynamic vegetation on precipitation is comparatively small $(<0.04 \mathrm{~mm} /$ day $)$. The synergy effect has no influence, on average.

\section{Introduction}

The Asian monsoon is the most complex and strongest monsoon system of the world, affecting human life since the first settlement in that region (Clift and Plumb, 2008). It consists of two nearly independent but also interacting monsoon systems, namely the East Asian and the Indian monsoon, and includes processes in the tropics as well as in the mid-latitudes (Lau et al., 2000). Monsoon systems are primarily driven by the seasonal differential heating between continents and oceans and the related land-sea temperature and pressure gradients. Their strength and the location of major monsoon precipitation, however, are also largely influenced by moist processes (Webster et al., 1998). Thus, each modification that has an impact on the hydrological cycle, energy storage or exchange between land, ocean and atmosphere affects the monsoon circulation, its onset and duration (Yasunari et al., 2006). This includes external forcings, such as changes in insolation, as well as interactions between the different components of the climate system, which might also have a strong influence on the regional climate and impose a large intraseasonal to multi-centennial variability on the system.

Published by Copernicus Publications on behalf of the European Geosciences Union. 
Paleoreconstructions reveal significant changes of the monsoon intensity during the Holocene. Around 6000 years before present (6k) the African as well as the Asian monsoon likely penetrated further inland, implying a wetter climate (e.g. Winkler and Wang, 1993; Kohfeld and Harrison, 2000; Ge et al. 2007; Maher, 2008) and a change in the vegetation distribution (e.g. Jolly et al., 1998; Yu et al., 2000). Early modelling studies related this enhancement of the monsoons to the impact of changing insolation on climate (e.g. Kutzbach and Otto-Bliesner, 1982; Harrison et al., 1998). Due to the variations in the Earth's orbit (mainly the precessional cycle), perihelion was reached in September $(6 \mathrm{k})$ instead of January at present time, yielding an increase of summer and decrease of winter insolation in the Northern Hemisphere relative to today (Berger, 1978). The seasonal cycle was enhanced in the Northern and reduced in the Southern Hemisphere, affecting the cross-equatorial ocean-land temperature gradient and thereby the monsoon flows. However, modelling studies just focusing on the direct response to orbital forcing tend to underestimate the monsoon expansion and associated increase of rainfall, at least over North Africa (Joussaume et al., 1999). More recently, research studies also consider ocean and/or vegetation interactions by performing coupled model simulations. Ocean-atmosphere interaction seems to further enhance the North African monsoon (Kutzbach and Liu, 1997; Braconnot et al., 2000; Liu et al., 2004). Regarding the Asian monsoon ambiguous results can be found. Several climate modelling studies report an increase of precipitation to be attributed to the ocean coupling (Hewitt and Mitchell, 1998; Braconnot et al. 2000, Wei and Wang, 2004). Other model results suggest an attenuation of Asian monsoon precipitation due to interactive ocean (Voss and Mikolajewicz, 2001; Liu et al., 2004 (for $11 \mathrm{k}$ ); Ohgaito and Abe-Ouchi, 2007; Li and Harrison, 2008, Marzin and Braconnot, 2009b).

Feedback studies concerning the role of the vegetation in Holocene climate change have mostly been applied to the African monsoon region (e.g. Claussen and Gayler, 1997; Broström et al., 1998; Irizarry-Ortiz et al., 2003; Levis et al. 2004; Hales et al., 2006). Nevertheless, some studies include or even focus on the Asian monsoon (e.g. Claussen, 1997; Texier et al., 2000, Wang, 1999; Diffenbaugh and Sloan, 2002; Li and Harrison, 2009). All model results agree that vegetation and land-surface feedbacks with the atmosphere could have enhanced the orbital-induced monsoon change during the Holocene.

To determine the contribution of the land-atmosphere and ocean-atmosphere interactions as well as their synergy to the climate change between the mid-Holocene $(6 \mathrm{k})$ and present-day (pre-industrial climate), we analyse a set of numerical experiments, performed by Otto et al. (2009a, b). They used a coupled atmosphere-ocean-vegetation model and applied a factor-separation technique (Stein and Alpert, 1993) to isolate the impact of different feedbacks on
Holocene climate change in the northern latitudes. Following the methods of Otto et al. (2009a) we repeat their study for the Asian monsoon region. Furthermore, we analyse all seasons separately.

After a short description of the model and the analysis methods in Sect. 2, we discuss the simulated climate and land-cover differences between mid-Holocene and present-day (Sect. 3). The contributions of land-atmosphere and ocean-atmosphere interactions as well as their synergy are further examined in Sect. 4.

\section{Methods}

\subsection{Model and experiments}

The results of this study are based on numerical experiments, performed by Otto et al. (2009b) with the comprehensive Earth system model ECHAM5-JSBACH/MPIOM, developed at the Max-Planck-Institute for Meteorology. In this model, the atmosphere is represented by ECHAM5 (Roeckner et al., 2003), extended with the land-surface scheme JSBACH (Raddatz et al., 2007). The model was run with the spectral resolution T31 (approx. $3.75^{\circ}$ ) and 19 vertical levels, following a hybrid sigma-pressure system. JSBACH includes the dynamic vegetation module of Brovkin et al. (2009). For the ocean, MPIOM (Jungclaus et al., 2006) is used at a horizontal resolution of approximately $3^{\circ}$ and 40 vertical levels.

The models have been tested against observation and reanalysis data. They capture the major structure of global and regional climate. A detailed comparison of ECHAM5 model output (resolution T63L31) and observations for the Central and East Asian region is presented by Cui et al. (2006). The simulated climate in our coupled control run does not substantially differ, although the deviation to the observed climate might be more pronounced due to the coarse resolution we chose (Roeckner et al., 2006).

The experimental set-up was designed to separate the contribution of the ocean-atmosphere interaction, the vegetation-atmosphere interaction and their synergy from the total climate change between mid-Holocene $(6 \mathrm{k})$ and present-day $(0 \mathrm{k})$ by applying the factor-separation technique (Stein and Alpert, 1993). Altogether, eight experiments were undertaken: four with present-day orbital configuration (set $0 \mathrm{k}$ ), four with mid-Holocene orbit (set $6 \mathrm{k}$ ). Each set contains a fully-coupled run, performed with the atmosphere-ocean-vegetation model (AOV), two simulations with the atmosphere either coupled to the vegetation or the ocean ( $\mathrm{AV}$ and $\mathrm{AO}$, respectively) and an atmosphere-only run (A). In these experiments, the non-interactive components were prescribed as boundary conditions from the present-day runs. Thereby, the ocean (in the experiments $\mathrm{AV}_{6 \mathrm{k}}, \mathrm{AV}_{0 \mathrm{k}}$, $\mathrm{A}_{6 \mathrm{k}}$ and $\mathrm{A}_{0 \mathrm{k}}$ ) was prescribed as monthly mean values of sea-surface temperature (SST) and sea-ice, taken from the 
present-day run $\mathrm{AOV}_{0 \mathrm{k}}$. The vegetation (in $\mathrm{AO}_{6 \mathrm{k}}, \mathrm{AO}_{0 \mathrm{k}}$, $\mathrm{A}_{6 \mathrm{k}}$ and $\mathrm{A}_{0 \mathrm{k}}$ ) was prescribed as fraction of land cover type per grid-box. Values were taken from $\mathrm{AOV}_{0 \mathrm{k}}$ for the experiments $\mathrm{AO}$ and from $\mathrm{AV}_{0 \mathrm{k}}$ for the atmosphere-only runs. Atmospheric composition was fixed at pre-industrial values in all simulations, e.g. $\mathrm{CO}_{2}$ concentration was set to $280 \mathrm{ppm}$. All simulations were brought to equilibrium before they were continued for another 600 years in total. To assess the robustness of our results, the entire simulation period of the final 600 years was subdivided into five subsequent periods of 120 years (Otto et al., 2009b). For each 120-year sub-period the sea-surface conditions (for simulations $\mathrm{AV}$ and $\mathrm{A}$ ) and the global vegetation pattern (for $\mathrm{AO}$ and $\mathrm{A}$ ) were prescribed from the corresponding 120-year period of the respective run. For example, for the first 120-year period of run $A_{0 k}$, sea-surface conditions and global vegetation pattern of the first 120-year period of run $\mathrm{AOV}_{0 \mathrm{k}}$ were taken, and so on. Thereby, individual members of each ensemble of five 120-year simulations do not have exactly the same boundary conditions. For example, the individual members of the ensemble of five 120-year runs $A_{0 k}$ do not have exactly the same ocean and land boundary conditions.

The results of this study are based on seasonal means of all periods (i.e. 600 yrs-mean). Further information on the setup of experiments is given in Otto et al. (2009a, b).

\subsection{Analysis methods}

Following the factor-separation technique (Stein and Alpert, 1993), the contribution of vegetation-atmosphere and ocean-atmosphere interactions, or feedbacks, and the synergy between these feedbacks to the difference between mid-Holocene and present-day (pre-industrial) climate are determined as:

Total climate change: $\triangle \mathrm{AOV}=\mathrm{AOV}_{6 \mathrm{k}}-\mathrm{AOV}_{0 \mathrm{k}}$

Response of the atmosphere: $\Delta \mathrm{A}=\mathrm{A}_{6 \mathrm{k}}-\mathrm{A}_{0 \mathrm{k}}$

Contribution of vegetation-atmosphere feedback:

$\Delta \mathrm{V}=\left(\mathrm{AV}_{6 \mathrm{k}}-\mathrm{AV}_{0 \mathrm{k}}\right)-\left(\mathrm{A}_{6 \mathrm{k}}-\mathrm{A}_{0 \mathrm{k}}\right)$

Contribution of ocean-atmosphere feedback:

$\Delta \mathrm{O}=\left(\mathrm{AO}_{6 \mathrm{k}}-\mathrm{AO}_{0 \mathrm{k}}\right)-\left(\mathrm{A}_{6 \mathrm{k}}-\mathrm{A}_{0 k}\right)$

Contribution of synergy: $\Delta \mathrm{S}=\Delta \mathrm{AOV}-\Delta \mathrm{A}-\Delta \mathrm{O}-\Delta \mathrm{V}$

In this study, we restrict our analysis to two climate parameters, the near-surface air temperature $(2 \mathrm{~m}$ above ground) and precipitation. Time and spatial averaging is explained in Sects. 2.2.1 and 2.2.2, respectively.

\subsubsection{Calendar}

Joussaume and Braconnot (1997) show that paleo-climate model results and their interpretation strongly depend on the chosen calendar. Due to the precession of the earth, not just the seasonal insolation but also the length of the seasons changes in time. Comparing seasons of the
Table 1. Start day and length of the seasons for the mid-Holocene and present-day orbital configuration, respectively. The seasons are defined on astronomical calendar, based on the time of vernal and autumnal equinox as well as summer and winter solstice. The beginning of the seasons is shifted backwards by three weeks.

\begin{tabular}{lcccc}
\hline & \multicolumn{2}{c}{$6 \mathrm{k}$} & \multicolumn{2}{c}{$0 \mathrm{k}$} \\
season & start & $\begin{array}{c}\text { length } \\
\text { (day) }\end{array}$ & $\begin{array}{c}\text { start } \\
\text { (days) }\end{array}$ & $\begin{array}{c}\text { length } \\
\text { (day) }\end{array}$ \\
\hline days) \\
\hline winter & 334 & 93 & 336 & 88 \\
spring & 62 & 94 & 59 & 93 \\
summer & 156 & 89 & 152 & 94 \\
autumn & 245 & 89 & 246 & 90 \\
\hline
\end{tabular}

mid-Holocene with present-day's, thus, requires an absolute time reference. Joussaume and Braconnot (1997) suggest the definition of seasons based on astronomical positions, i.e. vernal equinox, summer solstice, autumnal equinox and winter solstice. In accordance with the respective astronomical dates we calculate the seasonal averages for $6 \mathrm{k}$ and $0 \mathrm{k}$ from daily model output. However, to facilitate the comparison of our results with previous studies, which are usually based on present-day model (meteorological) calendar (e.g. summer = JJA), we shifted the seasons by three weeks. The day, each season starts at, as well as the length of the seasons is summarised in Table 1.

\subsubsection{Regions}

Asia is a continent with strong climatic and orographic contrasts. Affected by different circulation systems (Indian and East Asian monsoon, mid-latitude westerlies), deserts are located next to dense vegetated area, and tropical climate can be found as well as regions covered by snow for half of the year. Huge mountains and high-elevated plateaus as well as wet plains around large rivers form the landscape. Due to this heterogeneity it can be assumed that the atmospheric response to the orbital forcing and the strength of the feedbacks differ for different regions. This hypothesis is corroborated by reconstructions, revealing an asynchronous precipitation maximum in various parts of the Asian monsoon region (An et al., 2000), which indicates large spatial differences in the climatic change between the mid-Holocene and today. Our analyses show that even in regions influenced by only one of the above mentioned circulation systems the response of the different climate components locally varies. Therefore, we divided the Asian monsoon region into sub-areas, which differ with respect to orography and vegetation changes. Ad hoc, we define the following regions of interest: in the region of the large plain in East China, (referred to as YANG in the following) and in North-East China (NECH) we expect a clear signal of the East Asian monsoon, whereas in the 
Table 2. Description of the areas we consider in our feedback study. Listed are the abbreviation, geographic position (latitude and longitude of grid-box centers) as well as a short characterisation. For location and shape of the regions see also Fig. 1.

\begin{tabular}{|c|c|c|c|}
\hline Region & $\begin{array}{l}\text { Approximate } \\
\text { longitude }\left({ }^{\circ} \mathrm{E}\right)\end{array}$ & $\begin{array}{l}\text { Approximate } \\
\text { latitude }\left({ }^{\circ} \mathrm{N}\right)\end{array}$ & Description \\
\hline IND & $71.25-78.75$ & 12.99-24.12 & $\begin{array}{l}\text { Indian subcontinent (land only), } \\
\text { core region Indian monsoon }\end{array}$ \\
\hline INCPIN & $93.75-108.75$ & 12.99-20.41 & $\begin{array}{l}\text { Indochina Peninsula (land only), } \\
\text { tropical region, influenced by East Asian monsoon }\end{array}$ \\
\hline PAK & $56.25-75$ & $27.83-31.55$ & $\begin{array}{l}\text { includes parts of Pakistan, Afghanistan and Iran, } \\
\text { affected by the Indian monsoon }\end{array}$ \\
\hline $\mathrm{TP}$ & $75-101.25$ & $27.83-38.97$ & $\begin{array}{l}\text { Tibetan Plateau (model orography higher than } 2500 \mathrm{~m} \text { ), } \\
\text { affected by Indian and East Asian monsoon }\end{array}$ \\
\hline YANG & $105-120$ & $31.54-38.97$ & $\begin{array}{l}\text { Yangtze and Huanghe plain, } \\
\text { represents core region of the East Asian monsoon }\end{array}$ \\
\hline $\mathrm{NECH}$ & $116.25-135$ & $46.39-53.81$ & $\begin{array}{l}\text { Northeastern China, lower reaches of the Amur } \\
\text { river, affected by East Asian monsoon to some extent }\end{array}$ \\
\hline
\end{tabular}

regions PAK and IND of the Indian subcontinent, the Indian monsoon is likely to dominate climate dynamics. The areas roughly identified with the Tibetan Plateau (TP) and the Indochina Peninsula (INCPIN) are presumably affected by both monsoon systems. A detailed definition of the sub-areas is given in Table 2 and Fig. 1. Although these sub-regions cover only nine grid boxes in some cases, the differences between the areas, we used for the allocation, consistently stay the same regarding orography and vegetation change.

\section{Main characteristics of Central and East Asian climate and land cover changes}

\subsection{Climate change from $6 \mathrm{k}$ to present-day}

The climate in Central and Eastern Asia is influenced by three different circulation systems: the East Asian monsoon, the Indian monsoon and the mid-latitude westerlies. These systems are all strongly affected by the Tibetan Plateau. They in turn originate from different climate factors and are characterised by distinct seasonal cycles. Therefore, the regional climate is very heterogeneous, with arid and desert like conditions in the northwest, a general wet southern and eastern part and an alpine climate on the elevated Tibetan Plateau.

Before discussing the climatic impact of the dynamic ocean and vegetation (next section), we describe the main characteristics of the climate and land cover changes in the Asian monsoon and surrounding regions $\left(60-140^{\circ} \mathrm{E}\right.$, $\left.10-55^{\circ} \mathrm{N}\right)$. These results are based on the coupled experiments $\mathrm{AOV}_{6 \mathrm{k}}$ and $\mathrm{AOV}_{0 \mathrm{k}}$, averaged over all five periods (i.e. 600 yrs-mean). The long duration increases the significance and reliability.

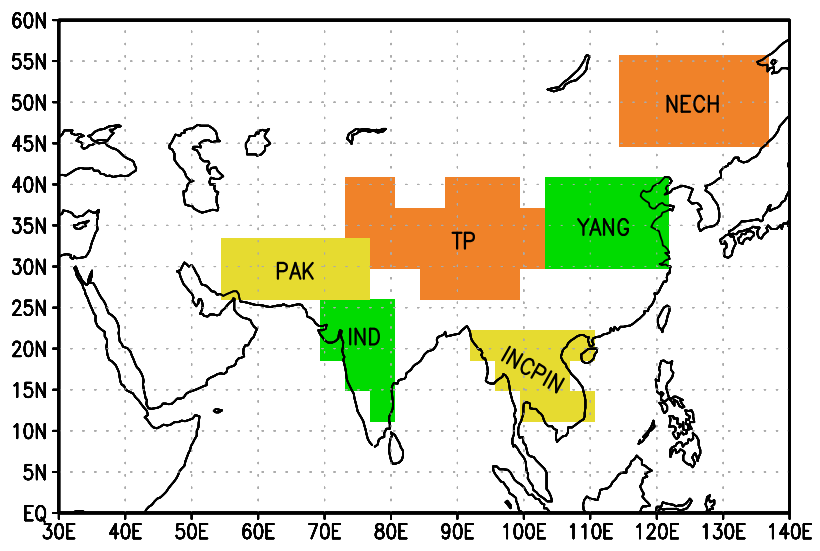

Fig. 1. Location of the areas we consider in our feedback study.

In our analysis we focus on near-surface air temperature (temperature $2 \mathrm{~m}$ above ground) and precipitation as the basic parameter characterizing monsoonal influenced climates. Both variables strongly determine the vegetation distribution.

In order to estimate the quality of our model results, we compare them with reconstructions. Since paleoclimate reconstructions are sparse and often derived from pollen assemblies, we confine the comparison to the vegetation change, assuming that the land cover reflects climate conditions. 


\subsubsection{Near-surface air temperature}

Figure 2 shows the geographic pattern of temperature changes between $6 \mathrm{k}$ and $0 \mathrm{k}$ for each season and as annual mean. For mid-Holocene spring, the model simulates lower near-surface air temperatures over the whole region $\left(60-140^{\circ} \mathrm{E}, 10-55^{\circ} \mathrm{N}\right)$ compared to present-day. Strongest cooling occurs in the northern part of India (up to $-2.8 \mathrm{~K}$ ) and on the Tibetan Plateau $(-1.5$ to $-2 \mathrm{~K})$.

Whereas summer temperature is increased in the regions north of $30^{\circ} \mathrm{N}$ with maximum amplitude of $3 \mathrm{~K}$, the western Pacific as well as the region between $20^{\circ} \mathrm{N}$ and $30^{\circ} \mathrm{N}$, particularly northern India and the southern rim of the Tibetan Plateau, experience a cooler near-surface climate under $6 \mathrm{k}$ orbital conditions (up to $-1.6 \mathrm{~K}$ ). The slightly higher temperatures over South India, Indochina and the adjacent Indian Ocean are negligible $(<0.5 \mathrm{~K})$.

With the exception of some grid-boxes south west of the Tibetan Plateau, an up to $3 \mathrm{~K}$ temperature rise occurs in all parts of the considered region in autumn (up to $2.2 \mathrm{~K}$ ).

For the winter season, the model results reveal lower near-surface temperatures over the continental area south of $55^{\circ} \mathrm{N}$ and slightly higher temperatures above the adjacent oceans. The strongest change occurs in the coastal areas and in the region south west of the Tibetan Plateau.

Averaged over the year, the Asian monsoon region experiences a cooling of up to $1.5 \mathrm{~K}$ (Northern India). Near-surface air temperatures in the other regions are slightly $(<0.5 \mathrm{~K})$ higher in $6 \mathrm{k}$ than in $0 \mathrm{k}$. The warming becomes more pronounced in the northern latitudes.

\subsubsection{Precipitation}

The seasonal precipitation changes between mid-Holocene and present-day are illustrated in Fig. 3. One has to be careful with the interpretation of precipitation changes. Due to the differences in the length of the respective seasons between $6 \mathrm{k}$ and $0 \mathrm{k}$, a higher mean precipitation-rate per day $(\mathrm{mm} /$ day) does not necessarily imply a higher seasonal sum ( $\mathrm{mm} / \mathrm{season})$.

On average, the region, affected by the Asian monsoon in spring, and adjacent oceans receive less spring precipitation (up to $-1 \mathrm{~mm} /$ day) under $6 \mathrm{k}$ orbital conditions, likely indicating a later onset of the summer monsoons. In all other parts of the region, precipitation is slightly enhanced, in particular on the Tibetan Plateau, where snowfall is increased by nearly $0.5 \mathrm{~mm} /$ day.

The mid-Holocene summer climate is characterised by more precipitation (per day) than today in most parts of Central and Eastern Asia, but the difference is often smaller than $1 \mathrm{~mm} /$ day. The strongest change occurs at the southern rim of the Tibetan Plateau, where the steep slope of the Himalaya induces an increase in precipitation of 3-4 $\mathrm{mm}$ /day for $6 \mathrm{k}$. In contrast, rainfall decreases in the north eastern Bay of Bengal and the East and South China Sea (up to $2 \mathrm{~mm} /$ day).

In autumn, the area gaining more precipitation in $6 \mathrm{k}$ is expanded to the adjacent oceans. Averaged daily precipitation is especially enhanced in the Indian monsoon region (up to $2 \mathrm{~mm} /$ day). A reduction of rainfall rate is only apparent at some grid boxes east of the Tibetan Plateau, the northern Bay of Bengal and in the non-coastal western Pacific.

In most parts of East China wintertime precipitation is decreased in $6 \mathrm{k}$ compared to present-day. The largest change on the continent occurs in the Yangtze-Plain (up to $-0.7 \mathrm{~mm} /$ day). The northern regions and India receive slightly more precipitation. Except for the Bay of Bengal (up to $-1.5 \mathrm{~mm} /$ day) all adjacent oceans experience an enhancement of precipitation rate (up to $1.5 \mathrm{~mm} /$ day).

On average, the annual precipitation rate is increased over land in $6 \mathrm{k}$ (up to $-1 \mathrm{~mm} / \mathrm{day}$ ), except for the Yangtze-Huanghe-Plain.

\subsection{Land cover change from $6 \mathrm{k}$ to present-day}

The differences in climatic conditions for $6 \mathrm{k}$ and $0 \mathrm{k}$ induce large-scale land cover changes (Fig. 4). The simulated vegetation changes are assigned to four categories, namely forest, shrub, grass and non-vegetated fraction of a grid box (in the following referred to as desert fraction). Overall, Central Asia is covered by more vegetation in $6 \mathrm{k}$, although the decrease in desert fraction is mostly small, not reaching changes higher than $10 \%$. Only the region south west of the Tibetan Plateau (ca. $60^{\circ} \mathrm{E}-75^{\circ} \mathrm{E}, 27^{\circ} \mathrm{N}-33^{\circ} \mathrm{N}$ ) and the margin area of the East Asian summer monsoon $\left(108^{\circ} \mathrm{E}-111^{\circ} \mathrm{E}, 40^{\circ} \mathrm{N}-48^{\circ} \mathrm{N}\right)$ experience a larger increase of vegetated area (up to $40 \%$ ). On the contrary, the desert in North Africa and Arabia is strongly reduced. In the transition zone between monsoon-influenced area and nearby desert or sparsely vegetated area, the fraction covered by any type of vegetation is controlled by rainfall. The Tibetan Plateau is a large orographic barrier, preventing a further inland penetration of the Indian (northward) and East Asia summer monsoon (westward), whereas the African monsoon is able to expand northward. Since most of the total precipitation in those regions can be attributed to the summer monsoons, changes in the amount of rain at the lee side of the Tibetan Plateau and thereby the reduction of the desert fraction must be small. Thereby, the Tibetan Plateau limits the expansion of vegetation north of the Plateau.

For the monsoon regions, where the moisture supply is sufficient, the model only simulates a change in the type of vegetation. In $6 \mathrm{k}$, more area is covered by forest instead of shrubs and grass, particularly in the region south of and on the Tibetan Plateau as well as Eastern China. In the Indian monsoon region, part of the grass is replaced by shrubs. 

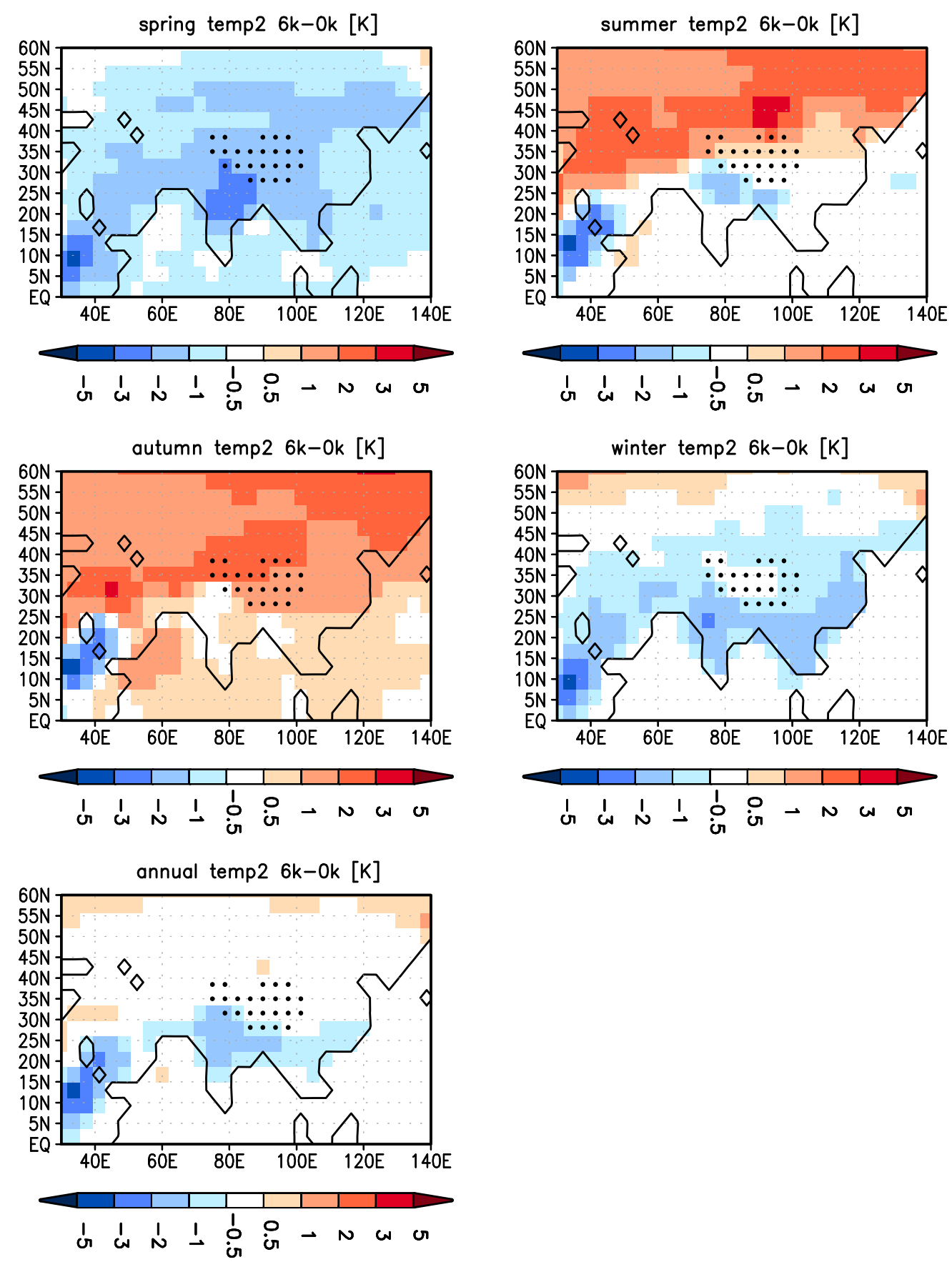

Fig. 2. Seasonal and annual averaged $2 \mathrm{~m}$-temperature anomalies $[\mathrm{K}]$ between mid-Holocene and present-day climate resulting from the coupled experiment AOV. Seasons are defined on astronomical calendar, based on the time of vernal and autumnal equinox and summer and winter solstice. The annual temperature anomaly is calculated on daily model output. Due to the different length of the respective seasons in mid-Holocene and present-day climate, the annual mean value is not the arithmetic average of the seasons. Stippled area indicates the Tibetan Plateau (orography in the model higher than $2500 \mathrm{~m}$ ).

Pollen analyses reveal a generally increased forest cover in the central and eastern parts of China (e.g. Ren and Beug, 2002; Ren, 2007) and a northwestward shift of the steppe-forest boundary of up to $500 \mathrm{~km}$ (Ren, 2007; Yu et al., 2000) for mid-Holocene climate. The model indicates a significant shift of forest to the west. However, in the low resolution of the model this shift is expressed by one single grid-box. A northward displacement cannot be detected. 

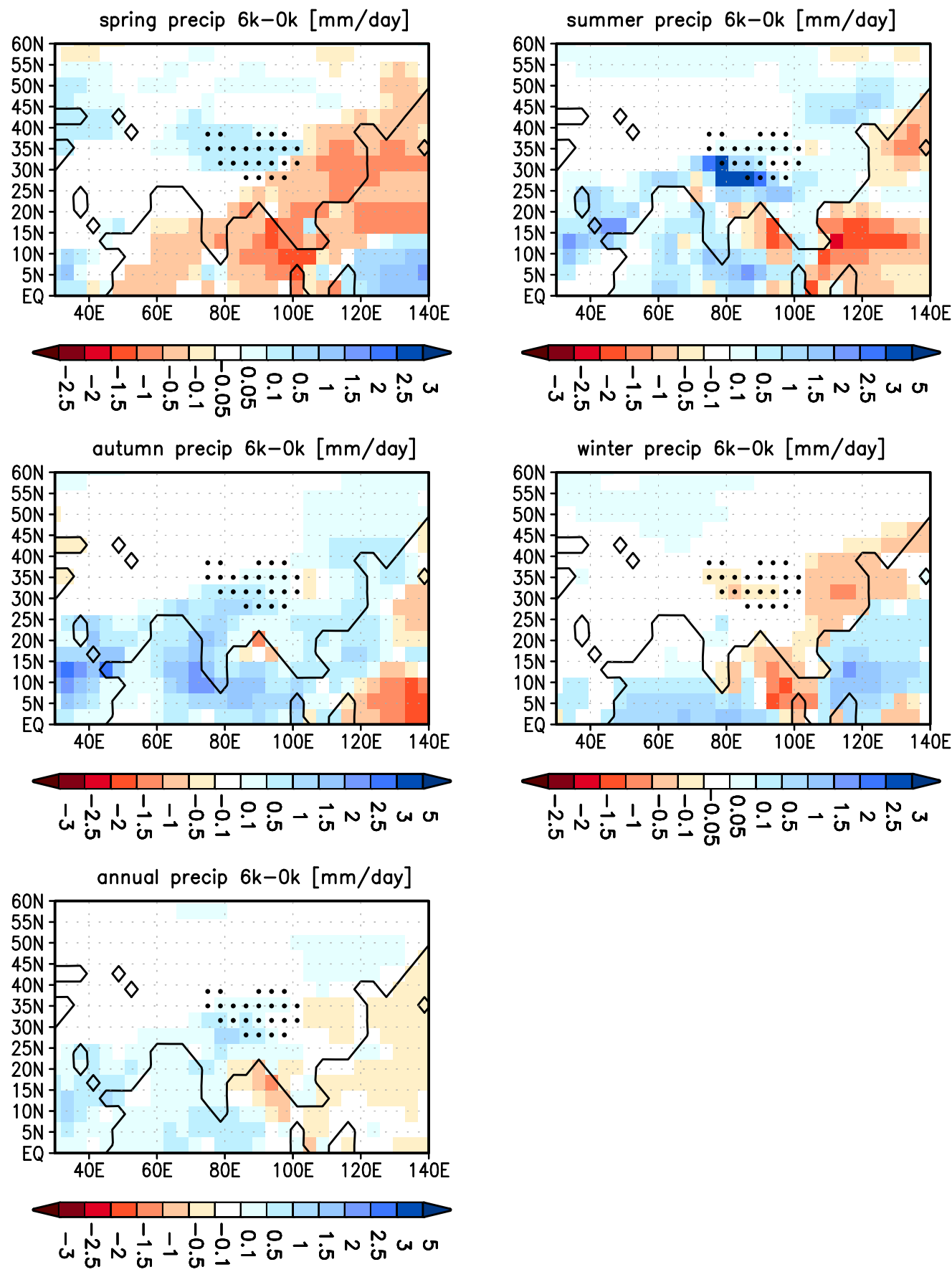

Fig. 3. Same as Fig. 2, but for seasonal and annual averaged precipitation anomalies [mm/day]. It has to be emphasized that, due to the differences in the length of the respective seasons between mid-Holocene $(6 \mathrm{k})$ and present-day ( $0 \mathrm{k})$ climate, a higher precipitation rate per day does not necessarily indicate a higher seasonal sum, i.e. a higher amount of precipitation per season. Please note differences in colour scales.

Ren (2007) reports a decline of arboreal pollen in Northeast China $\left(123-133^{\circ} \mathrm{E}, 40-52^{\circ} \mathrm{N}\right)$ from $6 \mathrm{k}$ to $0 \mathrm{k}$. Although the regions do not exactly coincide, the tendency of less forest in the northeastern part of China is also apparent in our model. Pollen reconstructions from the Tibetan Plateau indicate a spatial heterogeneous vegetation trend. Many records collected on the Eastern and Southern Tibetan Plateau reveal a reduction of moisture availability and forest cover since $6 \mathrm{k}$ (e.g. Herzschuh et al., 2006; Shen et al., 2006; Tang et al., 1999), which are proposed to be associated with a 

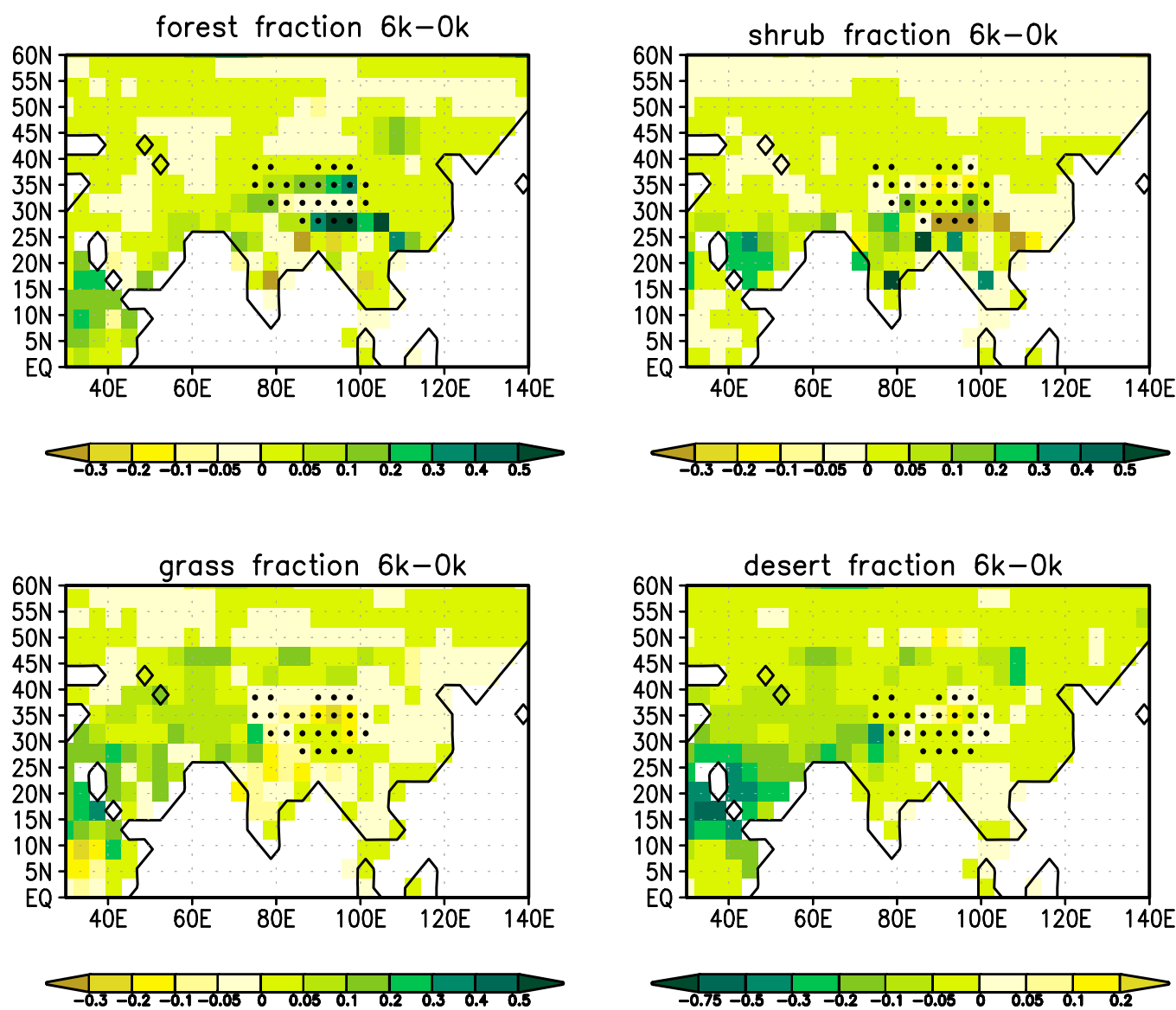

Fig. 4. Simulated land-cover change between mid-Holocene and present-day climate, given as fraction of forest, shrubs, grass and non-vegetated area (referred to as desert) per grid-box. Stippled area indicates the Tibetan Plateau (orography in the model higher than $2500 \mathrm{~m}$ ). Please note the change in colour scales.

gradual weakening of the Asian summer monsoon. However, some records also show comparably dry and even drier conditions in the mid-Holocene affecting the local vegetation composition (Zhao et al., 2009; Herzschuh et al., 2009). This inhomogeneous land cover trend is also obvious in the model results.

Given the coarse resolution of the model, the spatial distribution of the simulated vegetation changes between Mid-Holocene and present-day qualitatively agrees with reconstructions. However, the magnitude of changes differs. Whereas reconstructions suggest a decrease in forest cover of up to $90 \%$ (Ren, 2007; middle and lower reaches of the Yellow River and Huaihe River basin) our model reveals differences of less than 50\%, everywhere. However, no other reconstruction studies report such large vegetation change.

\section{The impact of dynamic vegetation and ocean on the climate change between $6 \mathrm{k}$ and present-day}

The impact of vegetation-atmosphere interaction, ocean-atmosphere interaction and of their synergy on the difference between mid-Holocene and present-day climate is calculated for each region and for each 120-year sub-period as well as for the whole 600-year simulation period. Even though the prescribed boundary conditions only slightly differ between each sub-period, the magnitude of the factor-contributions strongly varies, even with respect to the sign of factors, particularly for the vegetation contribution and the synergy. To assess the robustness of the factors over the entire simulation period, we conducted a standard student's t-test. Therefore, we define the five 120 -year sub-periods of each 600-year run as an individual realisation of an ensemble. The contribution of the respective factor is supposed to be robust if the t-value exceeds the 95\%-significance level. Please note that because of differing boundary conditions within each ensemble (see Sect. 2.1) 


\section{Temperature $[\mathrm{K}]$}
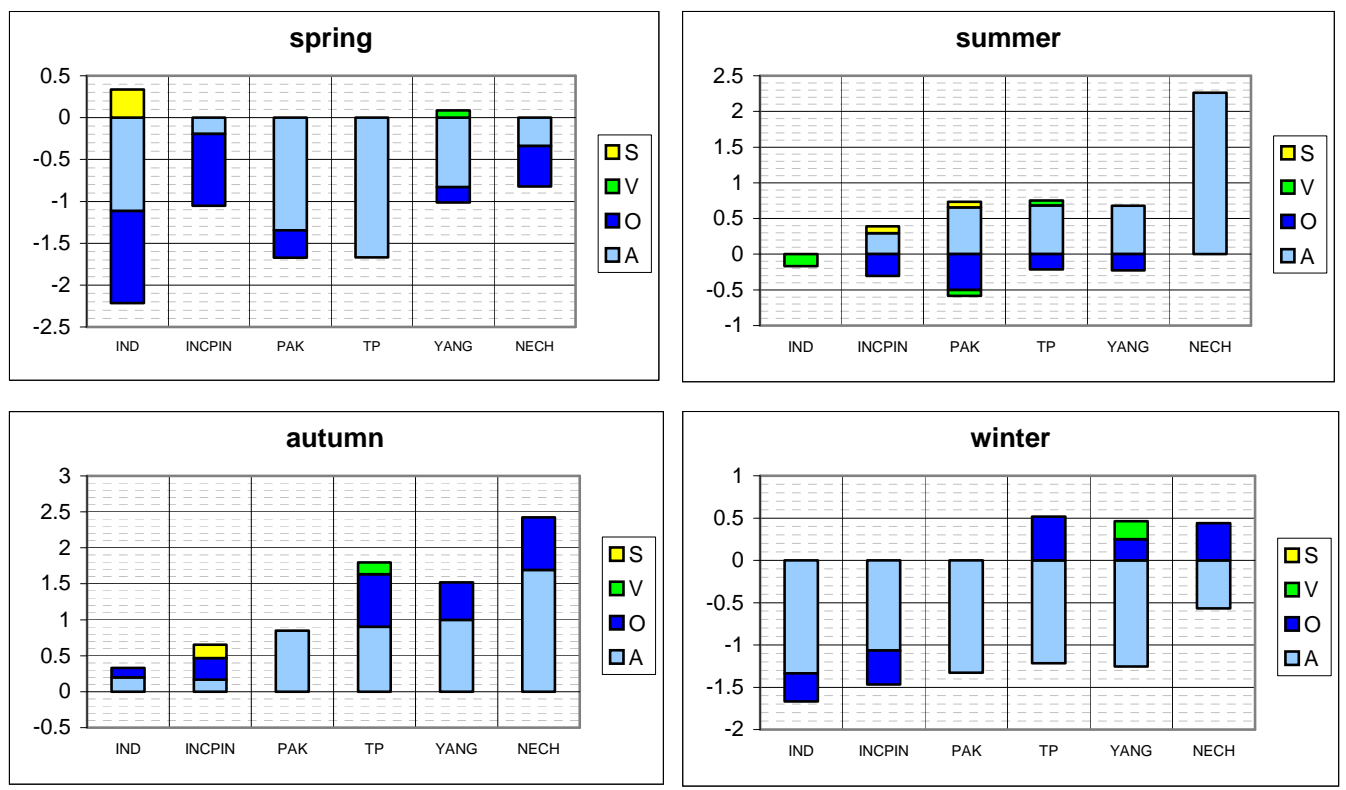

Fig. 5. Factors contributing to the seasonal temperature change between mid-Holocene $(6 \mathrm{k})$ and present-day $(0 \mathrm{k})$ climate for six regions in the area of the Asian monsoon. Only robust contributions are shown. Seasons are defined on astronomical calendar, based on the time of vernal and autumnal equinox as well as summer and winter solstice. Light blue colours show the results of the atmosphere-only run, i.e. the direct response of atmospheric dynamics (A) to changes in insolation. Dark blue colours represent the contribution of ocean-atmosphere-interaction $(\mathrm{O})$, including sea-ice dynamics. Green colours indicate the contribution of vegetation-atmosphere interaction (V). Yellow colours reveal the contribution of the synergy (S) between atmosphere - ocean and atmosphere - vegetation feedbacks. Please note the change in scales.

this test does not exclusively tests the significance of a pure contribution and synergy, but also includes effects from albeit small - changes in boundary conditions.

The summarising figures in this section depict mean values of the whole 600-year simulation period. Only significant, or robust, factors are shown. All factors for all sub-regions and seasons are presented in the Appendix (Figs. A1 and A2). The detailed presentation of results reveals strong variations in magnitude as well as in sign for some cases. Hence a small, or even missing, factor for the entire simulation period does not necessarily imply that the factor under consideration is always small.

\subsection{Near-surface air temperature}

\subsubsection{Direct response of the atmosphere to the orbital forcing}

Figure 5 illustrates the robust contributions of the ocean-atmosphere and vegetation-atmosphere interactions to the temperature change as well as their synergy and the direct response of the atmosphere to the orbital forcing as seasonal means for each defined area. Following the orbital-induced insolation change between $6 \mathrm{k}$ and $0 \mathrm{k}$, the direct reaction of the atmosphere causes an overall cooling in winter and spring and a warming in summer and autumn. Depending on region and season different mechanism influence this temperature change by affecting the local energy balance. Important parameters characterising the energy balance are summarised in Table 3 for the atmosphere-only run. As the change in evaporation between mid-Holocene and present-day climate has a strong effect on the surface temperature, the robust contributions of the different factors to the evaporation differences are additionaly shown in Fig. 6.

In spring, less insolation is received at the top of the atmosphere in $6 \mathrm{k}\left(10^{\circ} \mathrm{N}\right.$ : ca. $-10.5 \mathrm{~W} / \mathrm{m}^{2} ; 55^{\circ} \mathrm{N}$ : ca. -3.5 $\mathrm{W} / \mathrm{m}^{2}$ ). Nevertheless, the areas along the western Pacific (YANG, INCPIN) experience a relatively small cooling $(-0.83 \mathrm{~K}$ and $-0.2 \mathrm{~K}$, respectively). This can be attributed to a reduced cloudiness and surface evaporative cooling (warming effect, cf. Fig. 6) due to a later onset of the East Asian summer monsoon, which can partly compensates the temperature decline expected from the insolation change. In contrast, the latent heat flux in IND, TP and PAK is increased at the expense of the sensible heat flux (Table 3). This leads to a more effective surface cooling and contributes to the temperature change induced by the general smaller 
Evaporation [mm/day]
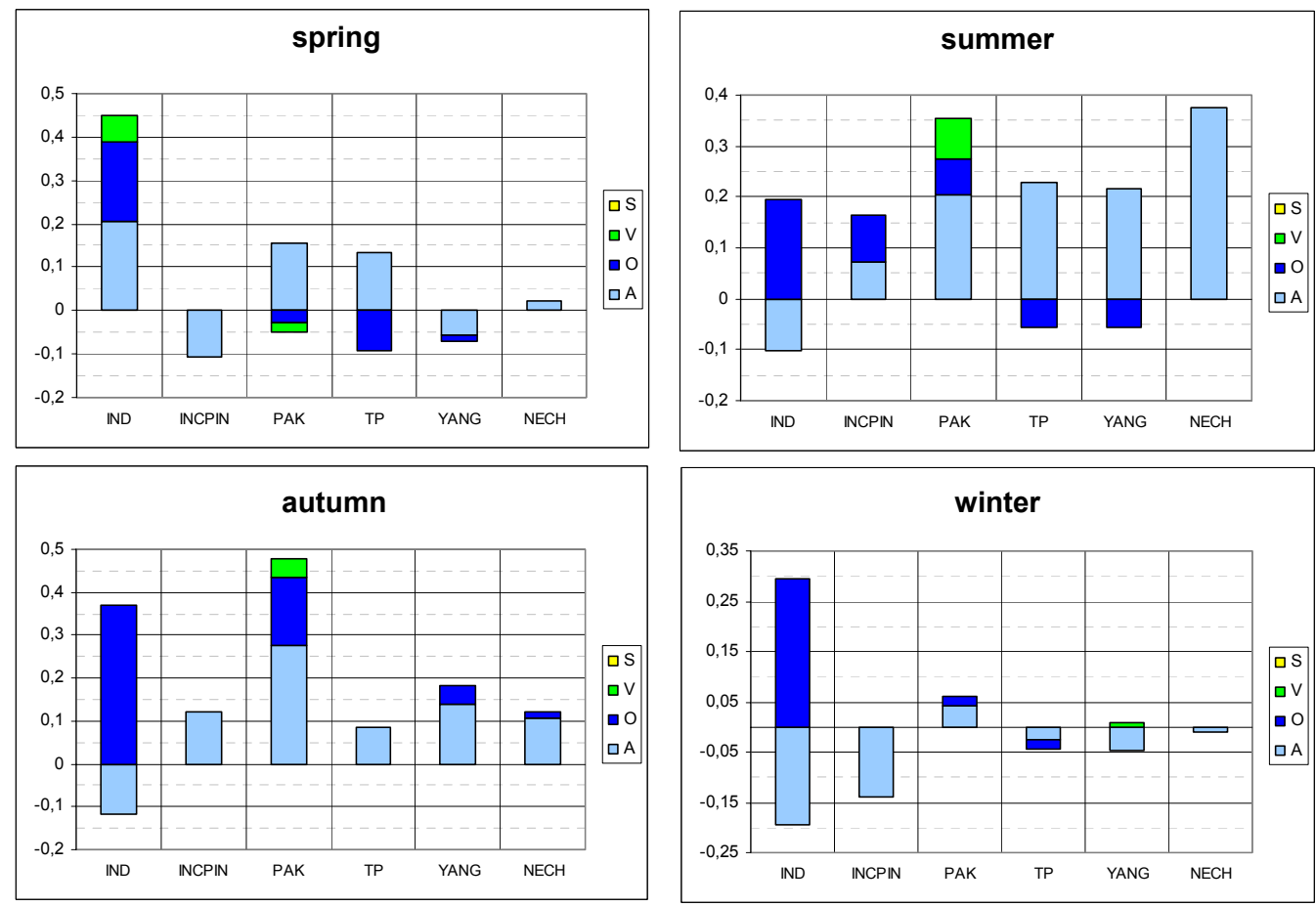

Fig. 6. Same as Fig. 5, but for evaporation anomalies [mm/day]. Please note the different scales.

insolation. Altogether, mid-Holocene climate in IND and PAK is colder than present-day climate by $-1.12 \mathrm{~K}$ and $-1.34 \mathrm{~K}$, respectively. The temperature difference is most pronounced on the Tibetan Plateau (TP: $-1.67 \mathrm{~K}$ ). Due to the orbital-induced temperature decline, the snowfall rate is enhanced on the Plateau, leading to a higher surface albedo (0.01), a reduction of absorbed solar energy and an amplification of the near-surface cooling. The snow-albedo feedback acting on TP, thus, likely creates the contrast to the surrounding areas. Less insolation results in an approx. $-0.34 \mathrm{~K}$ colder climate in NECH.

The near-surface temperature difference between $6 \mathrm{k}$ and $0 \mathrm{k}$ in summer is strongly determined by the direct response of the atmosphere to the orbital forcing, yielding more solar incoming radiation at the top of the atmosphere $\left(10^{\circ} \mathrm{N}\right.$ : $\left.+18.5 \mathrm{~W} / \mathrm{m}^{2} ; 55^{\circ} \mathrm{N}:+26.5 \mathrm{~W} / \mathrm{m}^{2}\right)$. In line with the latitudinal gradient of the insolation change, higher temperatures of up to $2.26 \mathrm{~K}$ in the northern region $(\mathrm{NECH})$ and slightly higher temperatures in the other regions $(0.29 \mathrm{~K}$ in INCPIN to $0.68 \mathrm{~K}$ in TP) are obtained (Fig. 5). Besides, more cloudiness and higher evaporation rates associated with a stronger summer monsoon (except IND) cool the surface and diminish the temperature rise, particularly in YANG, PAK and TP. In IND, the contribution of the direct effect is not robust.
The enhancement and later retreat of the Asian summer monsoon (see Sect. 4.2) also affects the temperature differences between mid-Holocene and present-day climate in the atmosphere-only simulations: Despite the negative latitudinal gradient of solar incoming radiation difference between mid-Holocene and present-day $\left(+9.5 \mathrm{~W} / \mathrm{m}^{2}\right.$ at $10^{\circ} \mathrm{N} ;+4 \mathrm{~W} / \mathrm{m}^{2}$ at $55^{\circ} \mathrm{N}$ ) the strongest temperature rise $(1.69 \mathrm{~K})$ occurs in the northern region $(\mathrm{NECH})$ and not near the equator. Near-surface temperature in IND and INCPIN increases only by $0.2 \mathrm{~K}$ and $0.17 \mathrm{~K}$, respectively. The later retreat of the Asian summer monsoon is accompanied by an enhanced cloudiness, resulting in a reduced net solar radiation at the surface in IND.

In winter, $2 \mathrm{~m}$-temperature is reduced in all regions due to less insolation $\left(-17.5 \mathrm{~W} / \mathrm{m}^{2}\right.$ at $10^{\circ} \mathrm{N} ;-6 \mathrm{~W} / \mathrm{m}^{2}$ at $\left.55^{\circ} \mathrm{N}\right)$. The largest cooling occurs in IND $(-1.33 \mathrm{~K})$, the weakest in NECH $(-0.57 \mathrm{~K})$. Since the cold temperatures enhance snow-fall rate in YANG and TP, these regions might experience an additional cooling caused by the snow-albedo feedback.

\subsubsection{Contribution of the dynamic ocean}

The simulated differences in sea-surface-temperature between mid-Holocene and present-day are depicted in Fig. 7. Due to the large thermal inertia of the water mass, differences in sea-surface temperatures lag differences in 
Table 3. Differences between mid-Holocene and present-day climate for certain parameters characterising the energy balance of the surface. Differences are calculated for each sub-region, based on results of the atmosphere-only run. Listed are incoming shortwave radiation at the top of the atmosphere $\left(\mathrm{SW}_{\text {in }} \mathrm{TOA}\right)$, sensible and latent heat flux (positive values indicate a higher flux from the surface to the atmosphere in $6 \mathrm{k}$ compared to $0 \mathrm{k})$, total cloud cover, net shortwave radiation at the surface $\left(\mathrm{SW}_{\text {net }}\right.$ surface $\left.\left[\mathrm{W} / \mathrm{m}^{2}\right]\right)$, net longwave radiation at the surface $\left(\mathrm{LW}_{\text {net }}\right.$ surface $\left.\left[\mathrm{W} / \mathrm{m}^{2}\right]\right)$, and near-surface temperature.

\begin{tabular}{|c|c|c|c|c|c|c|c|c|}
\hline (Atmosphere-only run) & spring & summer & autumn & winter & spring & summer & autumn & winter \\
\hline & \multicolumn{4}{|c|}{ IND } & \multicolumn{4}{|c|}{ INC } \\
\hline $\mathrm{SW}_{\text {in }} \mathrm{TOA}\left[\mathrm{W} / \mathrm{m}^{2}\right]$ & -9.34 & 20.85 & 8.67 & -15.55 & $-9,67$ & 20.27 & 8.96 & -16.07 \\
\hline Sens. heat flux $\left[\mathrm{W} / \mathrm{m}^{2}\right]$ & -6.26 & 1.99 & 2.19 & 0.32 & 0.54 & 1.87 & -0.82 & -2.08 \\
\hline Lat. heat flux $\left[\mathrm{W} / \mathrm{m}^{2}\right]$ & 5.84 & -2.84 & -3.42 & -5.74 & -3.15 & 2,11 & 3,53 & -4.14 \\
\hline Cloud Cover & -0.02 & 0.02 & 0.04 & 0.05 & $-0,04$ & 0.01 & 0.02 & 0.02 \\
\hline $\mathrm{SW}_{\text {net }}$ surface $\left[\mathrm{W} / \mathrm{m}^{2}\right]$ & -4.22 & -3.02 & -5.56 & -1226 & 0.08 & 2.76 & 1.77 & -9.56 \\
\hline $\mathrm{LW}_{\text {net }}$ surface $\left[\mathrm{W} / \mathrm{m}^{2}\right]$ & 4.13 & 2.10 & 4.51 & 5.57 & $-2,49$ & 0.82 & 1.40 & 2.26 \\
\hline \multirow[t]{2}{*}{ Temperature $2 \mathrm{~m}[\mathrm{~K}]$} & -1.12 & -0.05 & 0.20 & $-1,33$ & -0.20 & 0.29 & 0.17 & -1.07 \\
\hline & \multicolumn{4}{|c|}{ PAK } & \multicolumn{4}{|c|}{$\mathrm{TP}$} \\
\hline $\mathrm{SW}_{\text {in }} \mathrm{TOA}\left[\mathrm{W} / \mathrm{m}^{2}\right]$ & -8.00 & 22.82 & 7.56 & -13.36 & -7.37 & 23.48 & 7.06 & -12.33 \\
\hline Sens. heat flux $\left[\mathrm{W} / \mathrm{m}^{2}\right]$ & -4.56 & 2.83 & -0.27 & -3.30 & -7.80 & -4.50 & -1.69 & -3.07 \\
\hline Lat. heat flux $\left[\mathrm{W} / \mathrm{m}^{2}\right]$ & 4.53 & 5.94 & 8.02 & 1.27 & 4.31 & 6.45 & 2.50 & -0.75 \\
\hline Cloud Cover & 0.03 & 0.09 & 0.06 & 0.02 & 0.04 & 0.05 & 0.06 & 0.02 \\
\hline $\mathrm{SW}_{\text {net }}$ surface $\left[\mathrm{W} / \mathrm{m}^{2}\right]$ & -7.31 & -0.49 & -1.92 & -8.24 & -11.08 & -2.71 & -5.93 & -8.26 \\
\hline $\mathrm{LW}_{\text {net }}$ surface $\left[\mathrm{W} / \mathrm{m}^{2}\right]$ & 7.36 & 10.43 & 10.05 & 5.38 & 8.08 & 6.24 & 6.97 & 3.67 \\
\hline \multirow[t]{2}{*}{ Temperature $2 \mathrm{~m}[\mathrm{~K}]$} & -1.34 & 0.66 & 0.85 & -1.33 & -1.67 & 0.68 & 0.90 & -1.21 \\
\hline & \multicolumn{4}{|c|}{ YANG } & \multicolumn{4}{|c|}{$\mathrm{NECH}$} \\
\hline $\mathrm{SW}_{\text {in }}$ TOA $\left[\mathrm{W} / \mathrm{m}^{2}\right]$ & -7.13 & 23.74 & 6.7 & -11.90 & -4.36 & 25.78 & 4.89 & -7.52 \\
\hline Sens. heat flux $\left[\mathrm{W} / \mathrm{m}^{2}\right]$ & -0.80 & -0.30 & -0.65 & -0.89 & -1.79 & -0.84 & -1.50 & -1.25 \\
\hline Lat. heat flux $\left[\mathrm{W} / \mathrm{m}^{2}\right]$ & -1.63 & 6.30 & 4.05 & -1.33 & 0.62 & 10.87 & 3.07 & $-0,31$ \\
\hline Cloud Cover & $-0,01$ & 0.03 & 0.03 & 0.00 & 0.00 & 0.02 & 0.02 & 0.00 \\
\hline $\mathrm{SW}_{\text {net }}$ surface $\left[\mathrm{W} / \mathrm{m}^{2}\right]$ & -2.51 & 4.67 & 0.15 & -3.97 & -1.69 & 9.90 & -1.67 & -2.06 \\
\hline $\mathrm{LW}_{\text {net }}$ surface $\left[\mathrm{W} / \mathrm{m}^{2}\right]$ & 0.80 & 2.61 & 3.68 & 0.62 & 0.49 & 2.92 & 2.69 & $-0,19$ \\
\hline Temperature $2 \mathrm{~m}[\mathrm{~K}]$ & -0.83 & 0.68 & 1.00 & $-1,26$ & -0.34 & 2.26 & 1.69 & $-0,57$ \\
\hline
\end{tabular}

insolation by about one month. This causes a shift in the seasonal cycle of the oceanic contribution compared to the atmospheric response. Thus, the ocean-atmosphere feedback exerts a cooling in all considered parts of Asia in spring and summer (Fig. 5), thereby amplifying the atmospheric signal in the former and counteracting the direct response in the latter of these seasons. However, the magnitude of the ocean-induced cooling is generally small in summer as well as in spring (less than $-0.5 \mathrm{~K}$ in most areas). Only in India (IND) and on the Indochina Peninsula (INCPIN) the springtime temperature decrease associated with the atmosphere-ocean interaction reaches larger values of $-1.1 \mathrm{~K}$ and $-0.85 \mathrm{~K}$, respectively. In IND, this pronounced cooling is associated with a higher evaporation (+ca. $0.2 \mathrm{~mm} /$ day, Fig. 6) and hence, evaporative cooling. The temperature change is not robust for TP in spring nor for IND and NECH in summer.
In autumn, the contribution of the interactive ocean amplifies the direct effect and shows a warming in the same order of magnitude as the atmospheric response in most of the regions (Fig. 5). It ranges from $0.13 \mathrm{~K}$ in IND to $0.73 \mathrm{~K}$ in NECH and TP. No robust autumnal temperature change can be attributed to the ocean in PAK.

The ocean-atmosphere interaction leads to a cooling of the tropical regions (IND: $-0.33 \mathrm{~K}$, INCPIN: $-0.4 \mathrm{~K}$ ) in boreal winter, which intensifies the direct response of the atmosphere to the insolation change. Enhanced cloudiness and therewith less net solar energy at the surface (ca. $-5 \mathrm{~W} / \mathrm{m}^{2}$ ) causes the temperature decline in INCPIN. In the sub-region IND, a pronounced ocean-induced increase in evaporation (ca. $+0.38 \mathrm{~mm} /$ day) is found (see Fig. 6).

In the other regions, the ocean-atmosphere interaction counteracts the direct effect and leads to a reduction of the temperature difference given by the atmosphere-only run (Fig. 5, TP: $0.52 \mathrm{~K}$; YANG: $0.25 \mathrm{~K}$; NECH: $0.44 \mathrm{~K}$ ). The temperature change in PAK is not robust. 

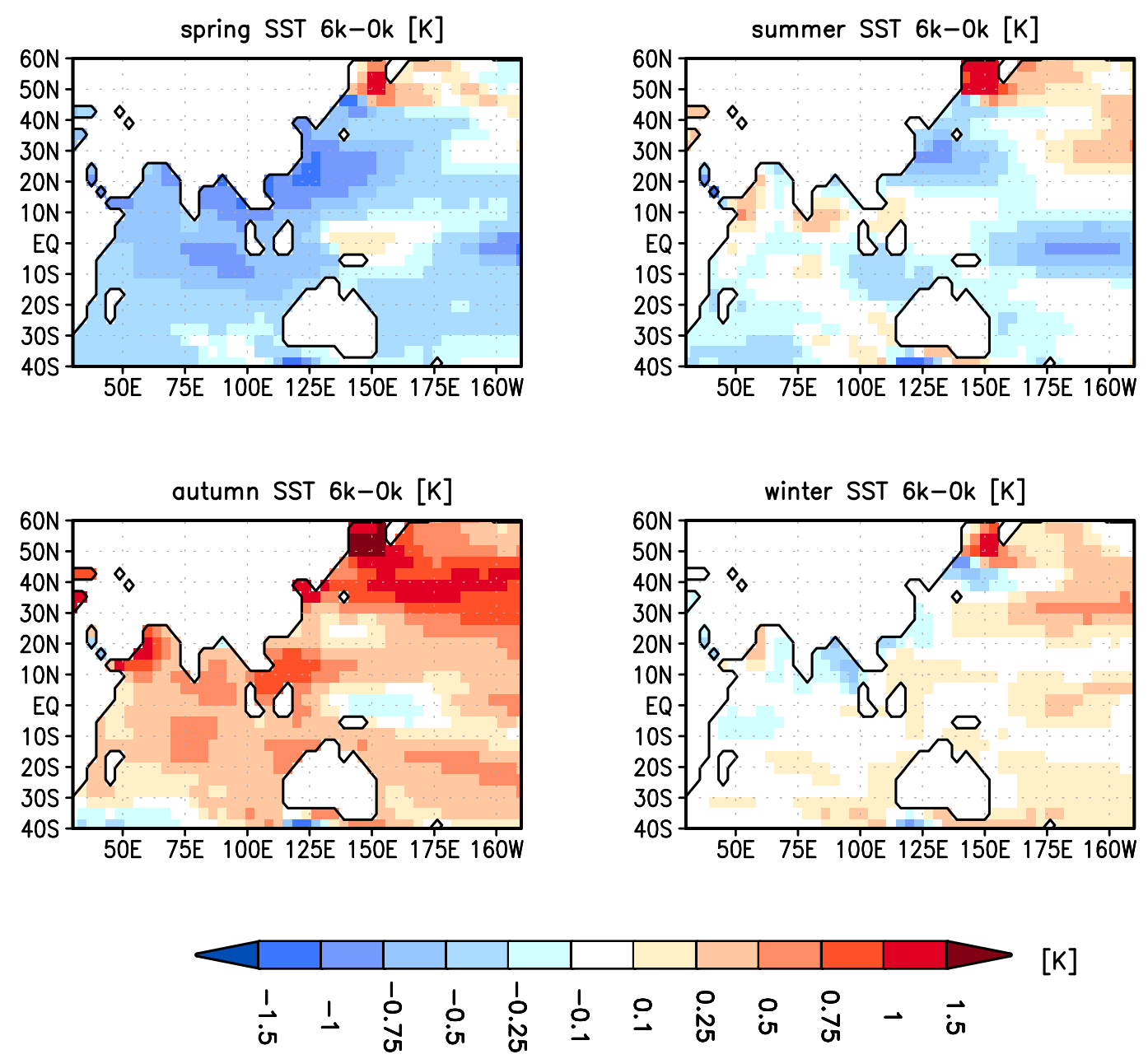

Fig. 7. Simulated differences in seasonal sea-surface-temperature $[\mathrm{K}]$ between mid-Holocene and present-day climate.

\subsubsection{Contribution of the dynamic vegetation}

As seen in Sect. 3.2, the vegetation change in the Asian monsoon region is small. Thus, one does not expect pronounced vegetation-atmosphere interactions in that area. Compared to the oceanic and atmospheric response, the averaged contribution of the dynamic vegetation to the Holocene temperature change is mostly negligible, reaching at most $0.22 \mathrm{~K}$ in YANG (winter). With few exceptions it reveals a warming in higher latitudes and a cooling in the tropical regions (IND, INCPIN) during the whole year. However, since the signal strongly varies between the different periods (see Appendix Fig. A1), in both, magnitude and sign, the dynamic vegetation-induced temperature change is robust only in a few cases (Fig. 5).

In spring, only YANG experiences a robust warming $(+0.04 \mathrm{~K})$. The slight increase in higher vegetation (more forest instead of shrubs) is accompanied by a reduction of surface albedo and a potential warming of the near-surface air, due to more absorbed shortwave radiation at the surface $\left(0.5 \mathrm{~W} / \mathrm{m}^{2}\right)$.

The slight (but robust) temperature decrease in the Indian monsoon region in summer (IND: $-0.17 \mathrm{~K}$; PAK: $-0.09 \mathrm{~K})$, is likely related to an increase of cloudiness and evapo-transpirational cooling of the surface due to an enlargement of the area covered by higher vegetation (shrubs instead of grass and desert). Interestingly, vegetation is the only factor yielding a robust signal for IND in summer. The Tibetan Plateau (TP) experiences a slight summer warming $(0.07 \mathrm{~K})$ attributed to dynamic vegetation.

This warming is still robust in autumn $(0.16 \mathrm{~K})$ and probably reflects an increase of net solar energy at the surface due to more forests and the associated decrease of surface albedo. 


\section{Precipitation [mm/day]}
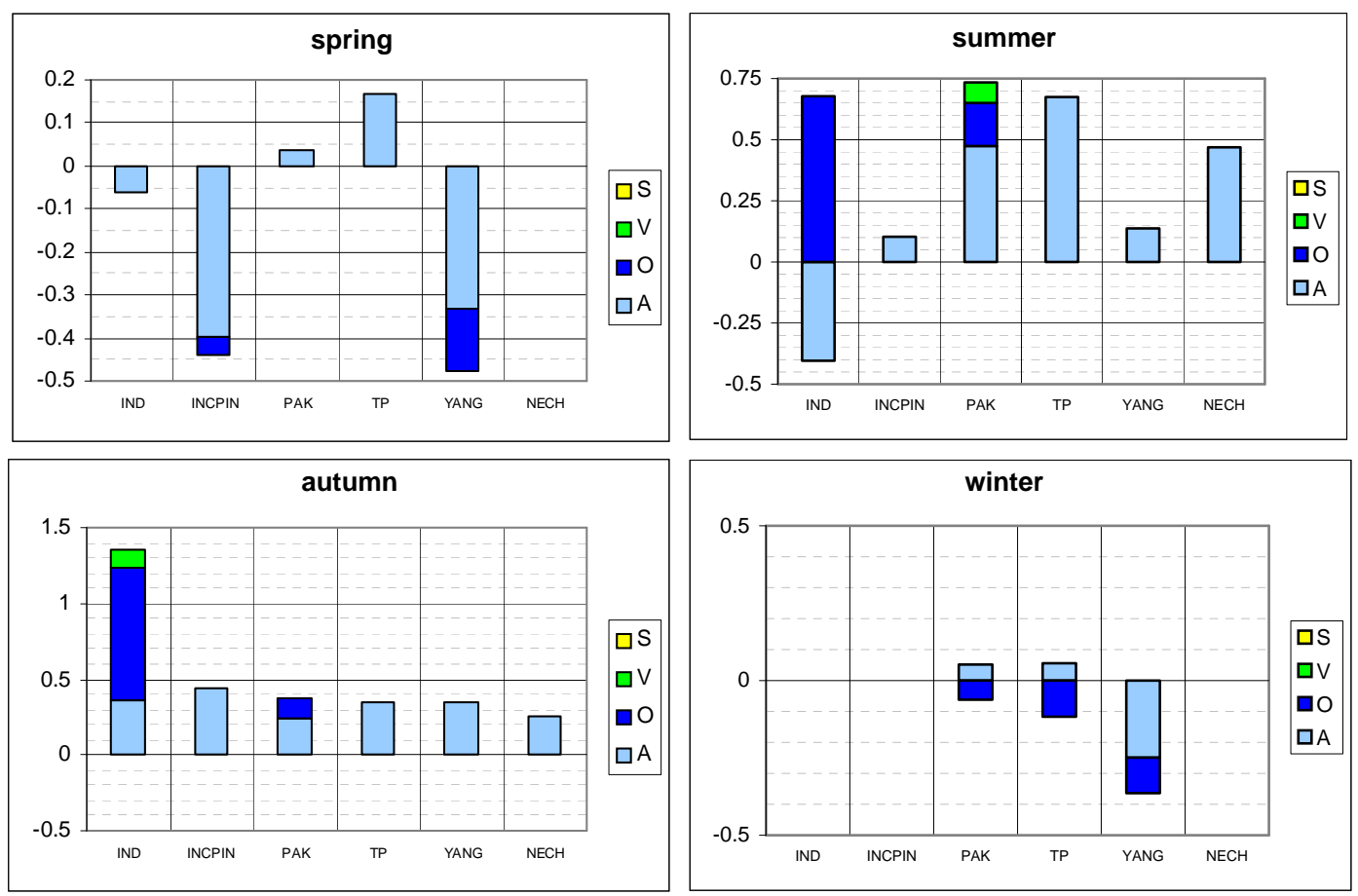

Fig. 8. Same as Fig. 5, but for precipitation anomalies [mm/day]. Please note the change in scales.

In winter, the temperature change attributed to the dynamic vegetation is only robust in YANG $(+0.22 \mathrm{~K})$. YANG is a region covered by snow in winter, so that the increase in forest fraction probably leads to a higher snow-masking effect and a reduction of the surface albedo (-0.01). Apart from the effect on the local energy balance the interactive vegetation leads to slight changes in local atmospheric dynamics. The increase in forest and vegetation cover northeast of the Tibetan Plateau (cf. Fig. 4) $103^{\circ} \mathrm{E}-117^{\circ} \mathrm{E}, 40^{\circ} \mathrm{N}-48^{\circ} \mathrm{N}$ ) warms the surface and regionally weakens the anticyclone, which develops in autumn over the cold land masses of the extratropical Asian continent (not shown). Total cloud cover as well as snow fall decrease in YANG, yielding an additional warming of the near-surface atmosphere.

\subsubsection{Contribution of the synergy}

The synergy between the ocean-atmosphere and vegetation-atmosphere feedback is small, but on average positive in nearly all regions and seasons. Its contribution to the temperature change tends to be larger in the southern regions (IND, PAK, INCPIN) than in the northern regions (YANG, NECH). Like the signal of the vegetation-induced temperature change, the synergy strongly varies between different 120-year periods. Thus, it is robust only in a few regions and seasons.
In spring, IND experiences a robust warming associated with the synergy (on average: $0.34 \mathrm{~K}$ ). The synergy contribution is also robust in INCPIN (summer and autumn) and in PAK (summer). No robust temperature change can be attributed to the synergy in winter.

\subsection{Precipitation}

\subsubsection{Direct response of the atmosphere to the orbital forcing}

The contributions of the dynamic ocean and vegetation to the precipitation change as well as their synergy and the direct response of the atmosphere to the orbital forcing are depicted in Fig. 8 as seasonal means for each defined area.

The dominant mechanism forming the monsoons is the thermal contrast between the land and the ocean. Thus, the seasonal cycle of monsoons is primary determined by the distribution of incoming solar radiation, which depends on the Earth's orbit around the sun (Webster et al., 1998; He et al., 2007). As expected, the change of the orbital parameter from $0 \mathrm{k}$ to $6 \mathrm{k}$ affects the simulated annual cycle of precipitation in the Asian monsoon region. The reduced solar energy input in spring postpones the East Asian summer and Bay of Bengal monsoon onset. Therefore, less spring precipitation is received in IND $(-0.06 \mathrm{~mm} /$ day $)$, 

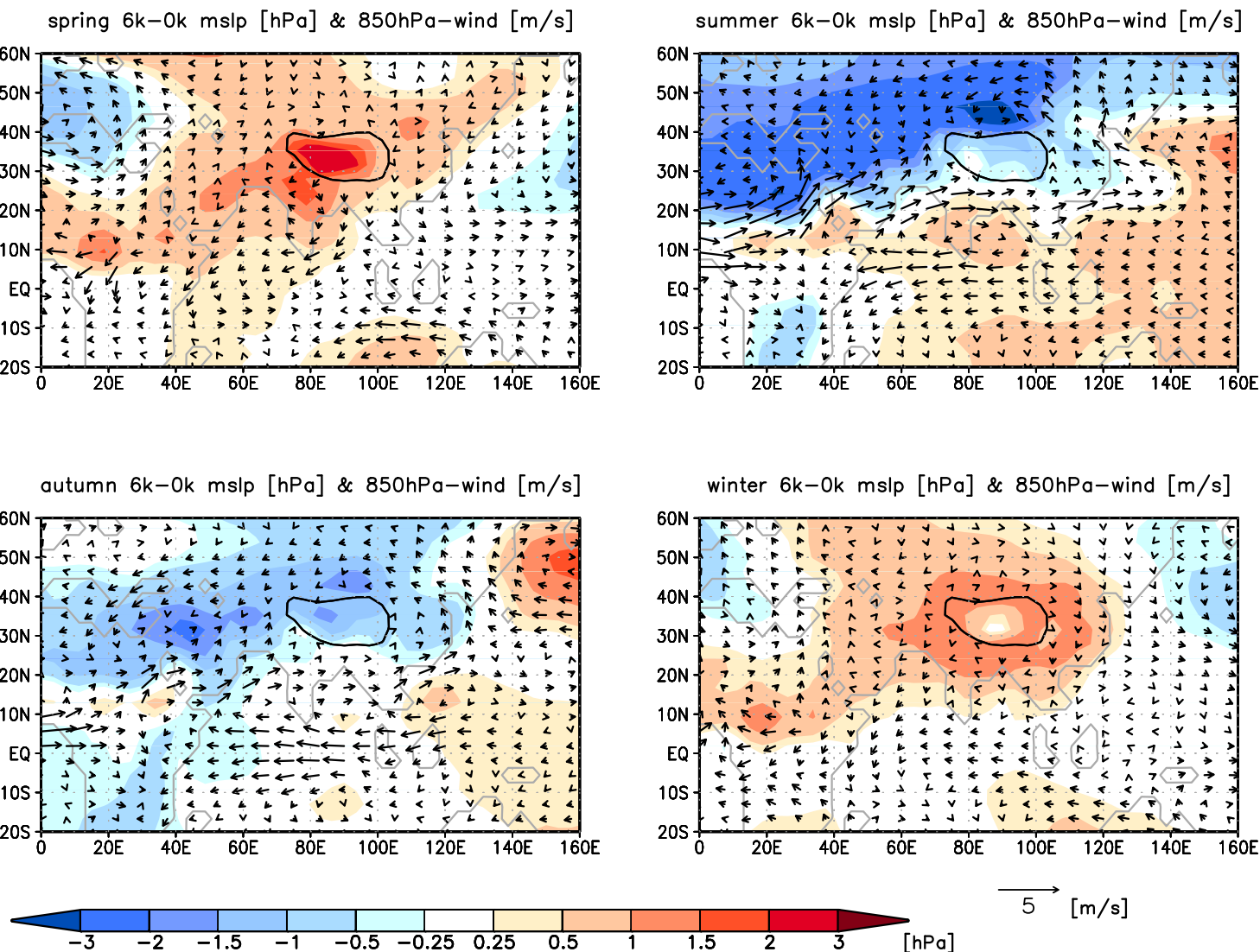

Fig. 9. Mean sea level pressure (shaded, [hPa]) and wind in $850 \mathrm{hPa}$ (vector, $[\mathrm{m} / \mathrm{s}]$ ) as simulated by the atmosphere-only run. Presented are anomalies between mid-Holocene and present-day climate on average over each season. Simulated present-day summer monsoon wind field $\left(\mathrm{A}_{0 \mathrm{k}}\right)$ can be seen in the Appendix (Fig. A3). The black solid line marks the Tibetan Plateau (orography in the model higher than $2500 \mathrm{~m}$ ). No wind vectors are shown, where the orography in the model exceeds $1500 \mathrm{~m}$ (approx. corresponding to the $850 \mathrm{hPa}-\mathrm{Niveau}$ ).

INCPIN $(-0.4 \mathrm{~mm} /$ day $)$ and YANG $(-0.33 \mathrm{~mm} /$ day $)$. The East Asian monsoon region is strongly affected, since less insolation weakens and shifts the western Pacific subtropical high southwards, reducing the East Asian monsoon flow onto the continent (Fig. 9). The regions PAK and TP experience an increase in precipitation by $0.04 \mathrm{~mm} /$ day and $0.17 \mathrm{~mm} /$ day, respectively, due to the orbital forcing. On the Tibetan Plateau (TP), the snow fall-rate is enhanced, reflecting the colder mid-Holocene climate in spring (Fig. 8).

As a consequence of the strong continental warming in summer, the large-scale circulation is modified. The upper tropospheric flow over Africa and the Central Asian continent is much more divergent in summer, except over South India and some parts of Indonesia (Fig. 10). This is related to an enhanced vertical uplift of moist air, more clouds and higher precipitation-rates in all considered regions except IND. Whereas the East Asian monsoon is intensified and penetrates further inland (Fig. 8; YANG: $+0.14 \mathrm{~mm} /$ day; NECH: $+0.47 \mathrm{~mm} /$ day), the atmosphere-only run suggests less precipitation (weaker monsoon) in India $(-0.4 \mathrm{~mm} /$ day $)$. Due to a low-level pressure anomaly in the area between Kazakhstan and the Arabian Sea (approx. $3 \mathrm{hPa}$, Fig. 9), the low level Indian monsoon flow is slightly shifted in $6 \mathrm{k}$ compared to present-day, strengthening the monsoon branch directed to the north Arabian Sea. Over Pakistan, this branch turns towards and streams along the Tibetan Plateau, resulting in more precipitation in PAK $(+0.47 \mathrm{~mm} /$ day $)$ and on the southern Plateau (TP: $+0.67 \mathrm{~mm} /$ day). By contrast, the monsoon flow in South India and the southern Bay of Bengal is attenuated. The changes in precipitation as well as outgoing longwave radiation (not shown) suggest a northward shift of the ITCZ in summer.

The atmospheric response to the orbital forcing leads to more autumn precipitation in the continental Asian monsoon region, especially in the coastal areas. On the contrary, less precipitation is received over the adjacent oceans, suggesting a later retreat of the summer monsoon system. The precipitation-rate is increased by about $0.25 \mathrm{~mm} /$ day in PAK to $0.44 \mathrm{~mm} /$ day in INCPIN (Fig. 8). 


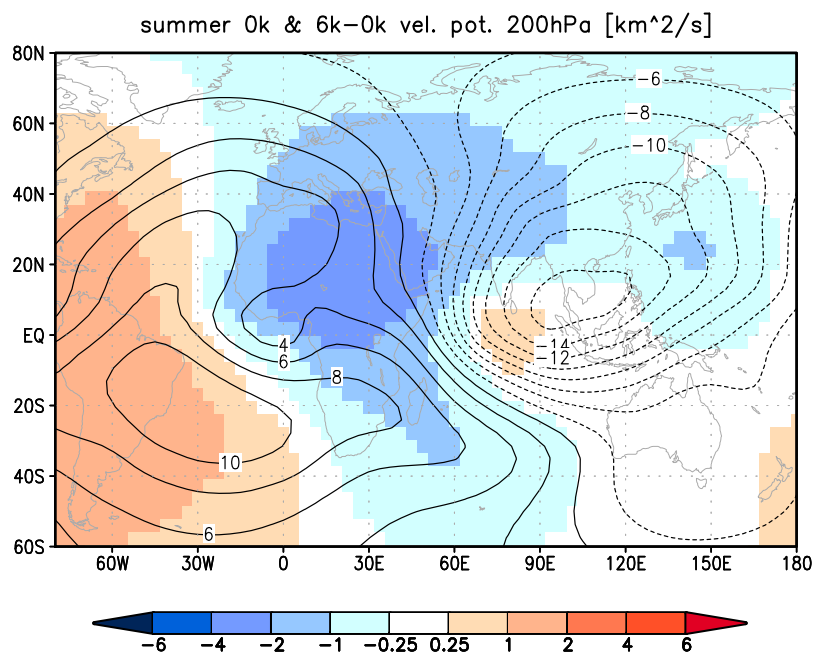

Fig. 10. Upper-tropospheric velocity-potential (200 hpa, $\left.\left[\mathrm{km}^{2} / \mathrm{s}\right]\right)$ as simulated by the atmosphere-only model, averaged over the summer season. Contour lines illustrate the velocity-potential under present-day orbital configuration. Shaded areas show the velocity-potential anomalies between $6 \mathrm{k}$ and $0 \mathrm{k}$. Negative values represent divergence, positive values convergence.

The change of wintertime precipitation is small compared to the other seasons and not robust in all regions. However, YANG is the only sub-region receiving appreciable precipitation in present-days winter monsoon. Whereas the direct effect yields an increase of precipitation in PAK $(0.05 \mathrm{~mm} /$ day $)$ and TP $(0.06 \mathrm{~mm} /$ day $)$ as a reaction to the orbital forcing, YANG experiences a pronounced reduction of precipitation by $-0.25 \mathrm{~mm} /$ day.

\subsubsection{Contribution of the dynamic ocean}

The oceanic impact on the seasonal precipitation distribution is mainly manifested in the change of evaporation and the modification of the large-scale and local circulation due to changed sea-surface temperatures (SSTs). Thus, lower SSTs in spring reduce evaporation and results in several high-pressure anomalies above the East and South China Sea as well as the northern Indian Ocean (see Fig. 11). The accompanied decrease of the moist-air advection from the ocean to the continent might be responsible for the reduction of precipitation in all regions (Fig. 8, Fig. A2). However, the signal is only robust in INCPIN $(-0.04 \mathrm{~mm} /$ day $)$ and in YANG $(-0.14 \mathrm{~mm} /$ day).

In summer, the pattern of large-scale circulation change due to the interactive ocean offers a much more divergent upper-tropospheric flow above the Arabian Sea and an increased convergence above the Pacific (Fig. 12). This coincides with a centre of enhanced evaporation in the South Arabian Sea and reduced evaporation in the East China Sea, influencing the precipitation change over the whole continent due to more water availability in the Indian monsoon and diminished water supply to the East Asian monsoon. Thus, IND $(+0.68 \mathrm{~mm} /$ day $)$ and the north coast of the Arabian Sea (including PAK: $+0.18 \mathrm{~mm} /$ day) experience a strong increase of rainfall-rate (Fig. 8). This oceanic-induced strengthening of the Indian summer monsoon is such as large, that it can overcompensate the direct effect $(-0.4 \mathrm{~mm} /$ day $)$ in India (IND), causing the wetter summer climate in that area in $6 \mathrm{k}$ compared to $0 \mathrm{k}$. In all other regions (INCPIN, TP, YANG, NECH), the change in summertime precipitation is not robust. Nevertheless, the interactive ocean tends to weaken the East Asian summer monsoon. Precipitation is particularly reduced above the adjacent ocean (see Fig. 13). However, apart from the reduction of water supply mentioned above, colder than present SSTs in the West Pacific (see Fig. 7) induce a high-pressure anomaly (anticyclone) and a slightly enhanced monsoon flow onto the continent (Fig. 11). These two mechanisms counteract and might lead to only small changes in the East Asian monsoon region, so that the East Asian summer monsoon is only little affected by the interactive ocean.

Due to the thermal inertia of the ocean, the sea surface is warmed the most in autumn (Fig. 7). SSTs are higher in most parts of the adjacent oceans, particularly in the north Arabian Sea. This leads to a warmer lower atmosphere and more evaporation, resulting in more water vapour in the atmosphere. These moist air masses are advected to the land, prolonging the rain period of the Indian summer monsoon. Thus, the most remarkable change occurs in IND $(+0.88 \mathrm{~mm} /$ day, Fig. 8$)$, where the ocean-atmosphere feedback triples the precipitation increase associated with the direct response of the atmosphere to the insolation change. In PAK, precipitation-rate rises by $0.13 \mathrm{~mm} /$ day. Like in summer, the East Asian monsoon rainfall-rate is only weakly affected by the interactive ocean and thus not robust.

In winter, the contribution of the interactive ocean to the precipitation change shows a robust signal in all regions, where the direct effect is robust. In PAK $(-0.06 \mathrm{~mm} /$ day $)$ and TP $(-0.12 \mathrm{~mm} /$ day $)$, the ocean-induced precipitation reduction partly compensates the atmospheric response to the insolation change. The atmospheric warming attributed to the ocean likely results in a decrease of cloud cover and precipitation in YANG $(-0.11 \mathrm{~mm} /$ day $)$.

\subsubsection{Contribution of the dynamic vegetation and synergy}

The seasonal precipitation-rates are only little affected by vegetation-atmosphere interactions. Nevertheless, the vegetation-atmosphere feedback (on average) mostly tends to amplify the direct response to the orbital forcing in all seasons except winter (see Fig. A2). As mentioned for temperature, the vegetation-induced precipitation change strongly varies between the different sub-periods and is thus only robust in two sub-regions. 

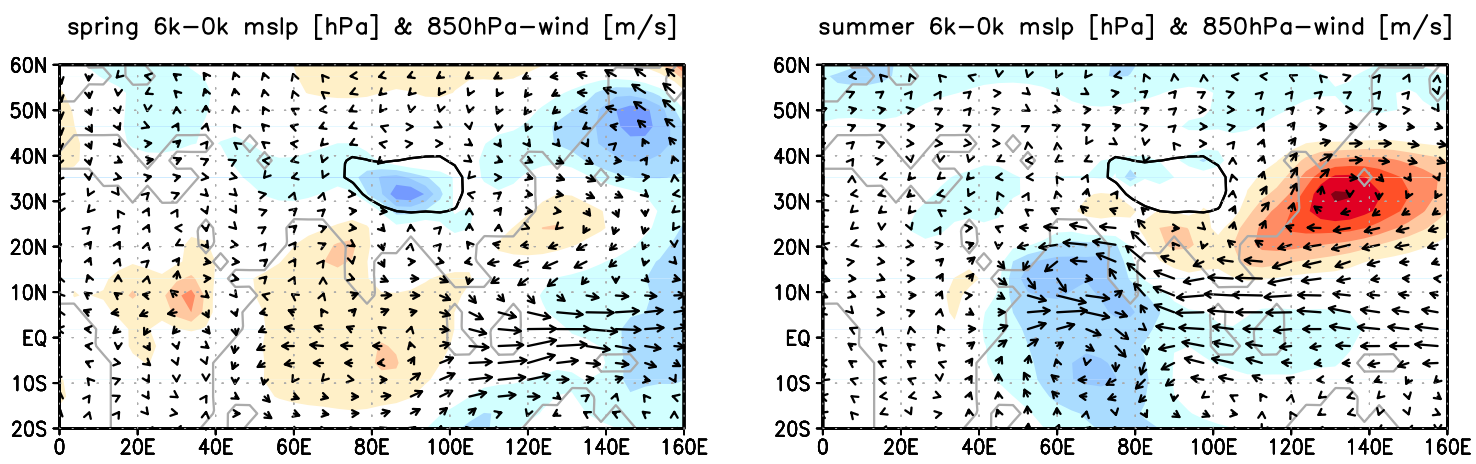

autumn $6 \mathrm{k}-0 \mathrm{k}$ mslp $[\mathrm{hPa}] \& 850 \mathrm{hPa}-$ wind $[\mathrm{m} / \mathrm{s}]$

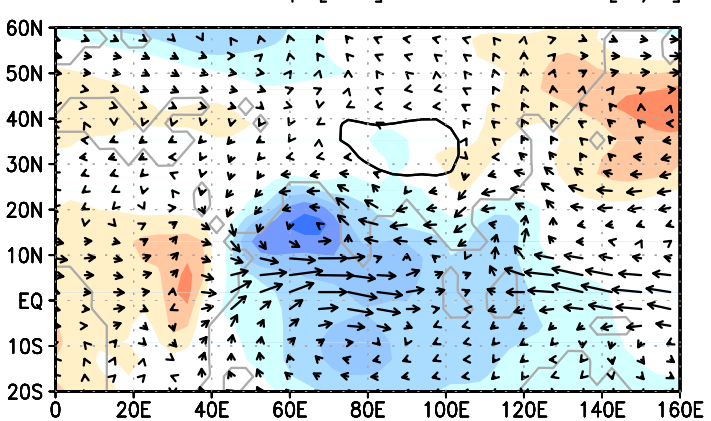

winter $6 \mathrm{k}-0 \mathrm{k}$ mslp $[\mathrm{hPa}] \& 850 \mathrm{hPa}$-wind $[\mathrm{m} / \mathrm{s}]$
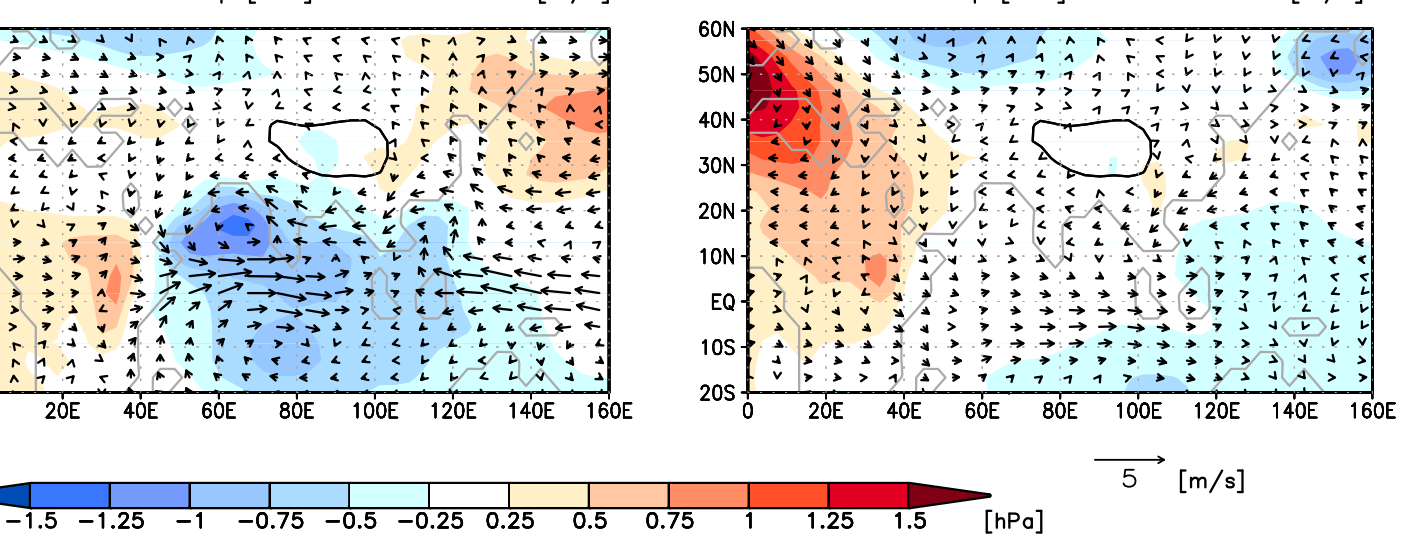

Fig. 11. Same as Fig. 9, but for the differences in wind and pressure field attributed to the ocean-atmosphere interaction.

It enhances differences between mid-Holocene and present-day precipitation over PAK in summer $(+0.08 \mathrm{~mm} /$ day $)$ and over IND in autumn $(+0.12 \mathrm{~mm} /$ day $)$. This effect can be attributed to the fact that during mid-Holocene, larger areas are covered by taller vegetation (shrubs, forest instead of grass and desert) in these regions, which, by their larger leaf area, tend to increase evapotranspiration and, thus, local precipitation.

The contribution of the synergy between the ocean-atmosphere and vegetation-atmosphere feedback to the precipitation change is small and not robust for any region and season.

\section{Summary and discussion}

The impacts of interactive ocean and vegetation on the climate change from mid-Holocene to present-day have been investigated for the Asian monsoon domain by applying the factor separation technique (Stein and Alpert, 1993) on a set of numerical experiments. As the topography in that region is very heterogeneous, different sub-areas are discussed separately. Temperature as well as precipitation changes are considered for all seasons, based on astronomical calendar.
Our analysis reveals, that the ocean-atmosphere feedback significantly influences the temperature and precipitation change between mid-Holocene and present-day, although most of the response can be attributed to the direct effect of the atmosphere. The interactive vegetation and synergy play a minor role in understanding the Asian monsoon climate change.

Averaged over all six sub-regions, the differences between mid-Holocene and present-day seasonal temperatures are given in Fig. 14a. Following the change in insolation, the Asian monsoon region experiences colder mid-Holocene climate of approximately $-1.32 \mathrm{~K}$ in spring and a warmer climate by some $1.29 \mathrm{~K}$ in autumn. On average, the summer temperature is increased by $0.59 \mathrm{~K}$ in $\mathrm{AOV}_{6 \mathrm{k}}$. This signal, however, is mainly caused by the strong warming in the sub-region NECH. On the contrary, the wintertime temperature reduction of $-0.97 \mathrm{~K}$ (on average) is determined by the colder mid-Holocene winter climate in the tropical regions (IND, INCPIN). Even though the variation of these seasonal temperature changes (i.e. warming in summer and autumn, cooling in winter and spring) is determined by the direct response of the atmosphere, the ocean alters the magnitude of the temperature difference. Due to its larger thermal inertia compared to the atmosphere, the 


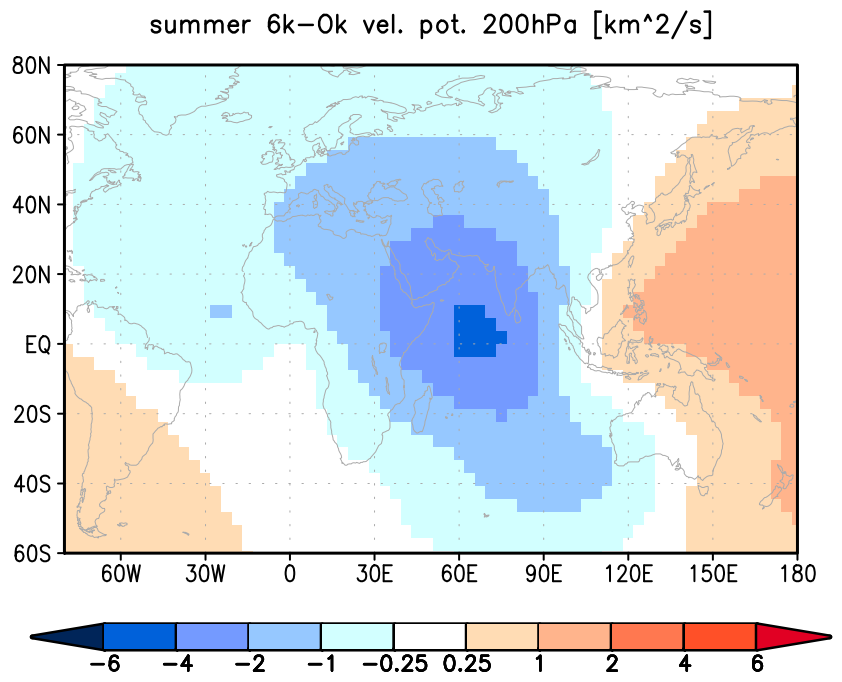

Fig. 12. Differences in upper-tropospheric velocity potential $\left(200 \mathrm{hPa},\left[\mathrm{km}^{2} / \mathrm{s}\right]\right)$ between mid-Holocene $(6 \mathrm{k})$ and present-day $(0 \mathrm{~K})$ climate, attributed to the ocean-atmosphere interaction and averaged over the summer season. Negative values represent divergence, positive values convergence.

ocean-induced response lags the insolation forcing by one month to one season. Therefore, the ocean-atmosphere feedback leads to an additional warming in autumn by $0.41 \mathrm{~K}$ and an additional cooling in spring by $-0.51 \mathrm{~K}$. In summer and winter, the contribution of ocean-atmosphere interaction counteracts the direct effect by $-0.24 \mathrm{~K}$ and $0.09 \mathrm{~K}$, respectively. Thus, the interactive ocean shifts the time of strongest warming from summer to autumn, and the strongest cooling from winter to spring. The small contribution of the interactive ocean in winter results from opposing temperature changes in the near-equatorial regions, i.e. cooling in IND and INCPIN, and warming in the other sub-regions.

As the monsoon dynamics mainly depend on the temperature gradient between the ocean and land, the shifted seasonal cycle of the oceanic response significantly affects the monsoon circulation. Due to the oceanic-induced cooling in summer and warming in winter, the ocean modifies the thermal processes in the monsoon system. The Tibetan Plateau is an area, where this mechanism might be particularly interesting. The Tibetan Plateau is a large elevated heat source in summer (March to October) and a weak heat sink in winter, exerting a strong impact on the Asian climate and the regional energy balance (Wu et al., 2007; Liu et al., 2007). By cooling the Plateau in summer and warming it in autumn, the ocean attenuates the magnitude of the heat source at the beginning of the monsoon season, which might affect the climate in the whole region. However, the detailed mechanism behind the feedback between ocean and the Tibetan Plateau is still not fully understood.

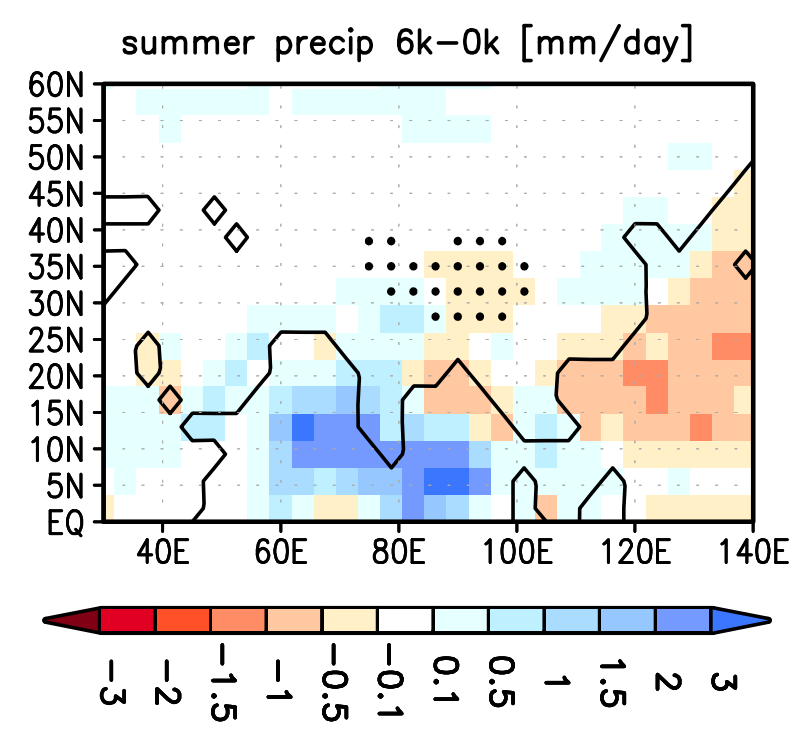

Fig. 13. Summertime precipitation changes [mm/day], which are attributed to the ocean-atmosphere interaction.

The contribution of synergy effect and interactive vegetation to the climate change is large for some simulation periods, but these signals are rarely robust. Robust effects are seen over the northern regions (TP, YANG), mainly due to changes in surface albedo. In the southern regions (IND, PAK, INCPIN), changes in evapotranspiration appear important. On average over all regions and periods, the influence of vegetation-atmosphere-interaction on mid-Holocene-present-day temperature differences are negligibly small. Only the synergy term tends to cause a slight warming from spring to autumn $(0.06 \mathrm{~K}$ to $0.1 \mathrm{~K})$.

Concerning precipitation, the strongest change is the shift and the strengthening of the summer monsoon season, causing a decrease in pre-monsoonal (spring) precipitation and an increased rainfall in summer and autumn between mid-Holocene and present-day climate. Whereas the East Asian monsoon is enhanced, the Indian monsoon flow is rearranged, leading to much more precipitation during mid-Holocene at the western and northern coast of the Arabian Sea as well as the southern rim of the Tibetan Plateau. As for temperature, the largest precipitation differences between mid-Holocene and present-day climate can be attributed to the direct effect of orbitally induced insolation changes. However, the ocean significantly contributes to the total response. Changed sea-surface temperatures in the coupled ocean experiments have a strong influence on evaporation and thus, the moisture supply to the monsoon systems. Furthermore, the ocean-atmosphere interaction modifies the large-scale circulation. The vegetation contributes only slightly to the precipitation change, mainly through the enhancement of 
temperature $[\mathrm{K}]$, all regions

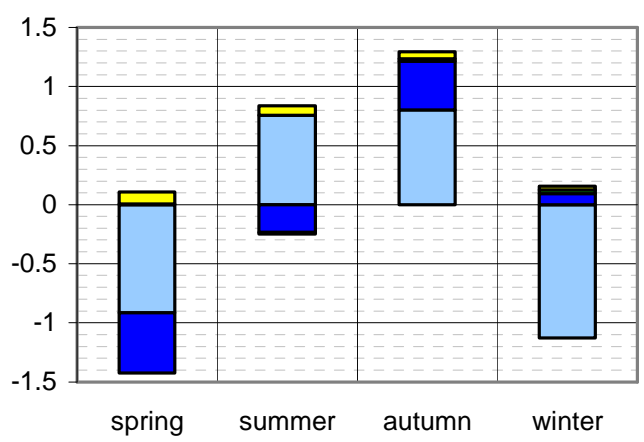

precipitation [mm/day], all regions

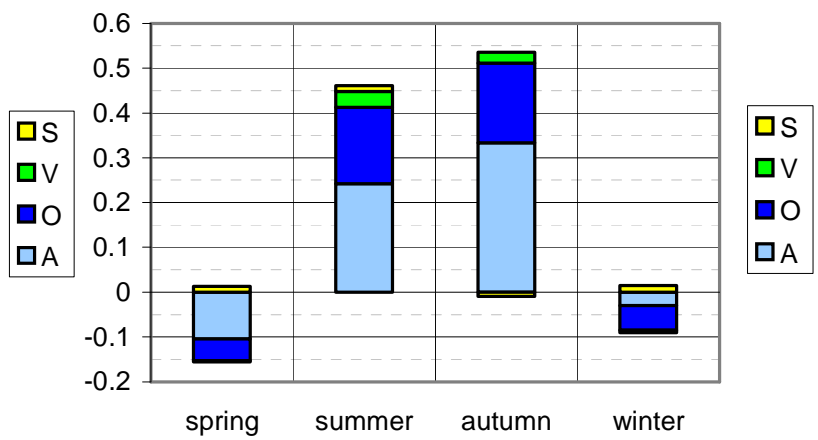

Fig. 14. Same as Fig. 5, but averaged over all six regions and periods. Robust as well as not robust contributions of the different factors are taken into account: left panel: temperature [K]; right panel: precipitation [mm/day].

evapotranspiration due to the enlargement of area covered by higher vegetation. The synergy has no influence.

Figure $14 \mathrm{~b}$ illustrates the precipitation differences between mid-Holocene and present-day climate on average over all regions. Mid-Holocene summer precipitation-rate is increased by $0.46 \mathrm{~mm} /$ day. Slightly more than $50 \%$ $(0.24 \mathrm{~mm} /$ day $)$ of this change can be attributed to the direct response of the atmosphere. Ocean-atmosphere interaction further amplifies the rainfall by $+0.17 \mathrm{~mm} /$ day. However, this signal is strongly determined by the increase in precipitation over the Indian monsoon region (particularly over IND). The East Asian summer monsoon tends to weaken due to the ocean-atmosphere interaction. Precipitation is reduced, particularly over the ocean. Over land the precipitation associated to the East Asian summer monsoon is only little affected by the ocean-atmosphere interaction. The interactive vegetation further contributes to the enhancement of the summer monsoon by $0.04 \mathrm{~mm} /$ day, mainly over the Indian monsoon region (PAK and IND).

In autumn, the most of the precipitation differences between mid-Holocene and present-day climate (in total: $0.53 \mathrm{~mm} /$ day) can be attributed to the direct response of the atmosphere to the insolation change $(0.33 \mathrm{~mm} /$ day $)$. As in summer, the ocean-atmosphere interaction and also the vegetation-atmosphere interaction further enhance the precipitation-rate by $+0.18 \mathrm{~mm} /$ day and $0.02 \mathrm{~mm} /$ day, respectively.

During mid-Holocene, springtime precipitation is reduced compared to present-day by some $-0.14 \mathrm{~mm} /$ day on average over all regions. Approximately two-third of this difference is caused by the direct response of the atmosphere to the insolation change, one-third can be attributed to ocean-atmosphere interaction. The reduced precipitation-rate in winter $(-0.08 \mathrm{~mm} /$ day $)$ is mostly associated with ocean-atmosphere feedback. The vegetation-atmosphere interaction has, on average, no influence in both seasons.
Although the ocean-atmosphere feedback appears positive averaged over all domains, our regional analyses reveal a negative feedback in some regions and seasons. The most remarkable example is IND, showing a strongly negative ocean-atmosphere feedback in summer. In that region, the atmosphere-only run suggests less precipitation in $6 \mathrm{k}$ compared to present-day. The ocean is able to overcompensate the direct effect, yielding to the wetter climate in $6 \mathrm{k}$. Whether the ocean-atmosphere feedback can be interpreted as either positive or negative, thus, depends on the spatial averaging (regionally versus entire monsoon region).

Before discussing our model simulations in the context of other studies, we compare our results for the Asian monsoon region with the results of Otto et al. (2009a) for the high northern latitudes.

Otto et al. (2009a) investigated the contribution of vegetation-atmosphere and ocean-atmosphere interactions to the near-surface air temperature change between mid-Holocene and present-day, based on the same set of experiments as in this study. They focused on the region north of $40^{\circ} \mathrm{N}$. Despite the very different circulation systems determining the climate in the Asian monsoon region and the northern latitudes, the influence of feedbacks and the direct response of the atmosphere to the orbital forcing are on average similar. Differences between mid-Holocene and present-day temperature in both regions can mostly be attributed to the direct effect of changed insolation, modified by ocean-atmosphere interactions. The summer temperature rise is twice as large in the northern latitudes as in the Asian monsoon region. In autumn, the region north of $40^{\circ} \mathrm{N}$ experiences a stronger temperature increase (ca. $1.8 \mathrm{~K}$ ) due to the orbital forcing, although the positive insolation change is more pronounced in the tropics. On the one hand, this can be attributed to increased evaporation in the monsoon region, leading to a cooling of the near-surface atmosphere. On the other hand, the pronounced temperature rise north of 
$40^{\circ} \mathrm{N}$ reflects the large influence of the ocean-atmosphere feedback on the northern latitude temperature difference between mid-Holocene and present-day. Mainly due to changes in sea ice, the ocean-atmosphere feedback can even change the sign of the response of the system to orbital forcing in the regions north of $40^{\circ} \mathrm{N}$ : mid-Holocene winter at northern latitudes is warmer than today by appr. $0.3 \mathrm{~K}$ despite weaker insolation during that season. The vegetation-atmosphere feedback plays a minor role in both regions. The reason for this is currently being investigated. For the Asian monsoon, we tentatively attribute the small effect of vegetation-atmosphere interaction to mid-Holocene - present-day climate difference to the fact that our model yields only small changes between mid-Holocene and present-day vegetation coverage. Although the model captures the main vegetation trend in the Asian region, the simulated change in forest cover is much smaller than found in reconstructions (e.g. Ren, 2007). Therefore, the model presumably underestimates the vegetation-atmosphere interaction. Further studies will have to focus on a detailed comparison of simulated and reconstructed climate using numerical experiments with much higher spatial resolution to capture the effect of strong variation in orography on atmospheric dynamics.

Comparison of our results with previous model studies is difficult, because a factor separation has not yet been applied to mid-Holocene model experiments for the Asian monsoon region. Furthermore, most studies concentrate on the summer season. If comparable, our results are in line with recent studies. Like most of the models with interactive ocean and vegetation considered in PMIP2 (Paleoclimate Modeling Intercomparison Project, Phase 2, Braconnot et al., 2007b) our model reveals a pronounced summertime cooling in north India (up to $2 \mathrm{~K}$ ) and a warming outside the tropical monsoon region (up to $3 \mathrm{~K}$ ) as response to the orbital forcing. Our model also simulates the increase in precipitation associated with the enhancement of the summer monsoons reported by these studies. Nevertheless, the sign and magnitude of the different feedbacks calculated in our model partly deviate from other studies, particularly concerning precipitation. The atmosphere-only run suggests less summer precipitation in India (IND), the Bay of Bengal as well as the South China Sea and more precipitation on the southern Asian continent compared with the coupled simulations. Whereas this shift in ITCZ is also seen in other model studies above the ocean (Marzin and Braconnot, 2009a; (PMIP1) Braconnot et al., 2007a), a reduction of summer precipitation on land (India) is only detected in a few model simulations (Ohgaito and Abe-Ouchi, 2007 (annual); $\mathrm{Li}$ and Harrison, 2008). The spatial distribution as well as the magnitude of the annual/summer precipitation change attributed to the atmospheric response corresponds well with these two studies, although Li and Harrison (2008) suggest a more enhanced summer monsoon in South China.
Concerning the ocean-atmosphere feedback, our results confirm the conclusion that the ocean rather suppresses the direct atmospheric response in large parts of the Asian monsoon region in the summer season (Liu et al. 2004; Ohgaito and Abe-Ouchi, 2007; Li and Harrison 2008, Marzin and Braconnot, 2009b). But our results do not show an overall ocean-induced weakening of the summer monsoon like the simulations in theses studies. Large parts of the Indian monsoon region (incl. IND and PAK) experience more precipitation due to the ocean-atmosphere feedback, counteracting the precipitation decrease suggested by the atmosphere-only run (IND). The precipitation in the East Asian monsoon region tends to decrease, particularly above the ocean. On average, the precipitation is enhanced (positive ocean-atmosphere feedback) on the continent, in summer as well as in autumn.

The vegetation-atmosphere interaction can only be compared to other model results with respect to the temperature change. The contribution of interactive vegetation tends to be weaker in our model (smaller than $0.5 \mathrm{~K}$ in all seasons) than in simulations with prescribed mid-Holocene vegetation (e.g. Diffenbaugh and Sloan, 2002; Zheng et al., 2004). Diffenbaugh and Sloan (2002) suggest temperature change between $-2 \mathrm{~K}$ and $+4 \mathrm{~K}$ in the Asian monsoon region for summer and spring. The results of Zheng et al. (2004) are in the same order of magnitude $(0 \mathrm{~K}$ to $3 \mathrm{~K}$ in winter). The spatial distribution of the change is also different to our simulations. In particular, our model does not capture the large vegetation-induced winter warming in China like in Zheng et al. (2004) and proposed by reconstructions (Yu et al., 2000). This might be a consequence of the underestimated simulated vegetation change for that region. Regarding the coupled AOV-simulations of PMIP2 (Braconnot et al., 2007b), our results are within the range of magnitude of the contribution of vegetation-atmosphere interaction (summer season), but the vegetation-atmosphere feedback strongly varies between the different participating models.

Although our results provide a broad insight into the feedback mechanism, which might be involved in the Holocene Asian monsoon climate change, the magnitude of the feedbacks still requires further discussion. Slightly different boundary conditions (SST and sea-ice) lead to a high variability in the contribution of vegetation-atmosphere feedback and synergy to the overall signal as shown in the five different simulation periods. In most cases, both factors are not robust in any of the regions. In addition, our analyses reveal that, whether a feedback (e.g. ocean-atmosphere feedback) appears positive or negative, strongly depends on the spatial averaging. For such heterogeneous and climatic complex area as the Asian Monsoon region it is thus necessary to perform model experiments with high spatial resolution, probably revealing a better representation of the local climate. 

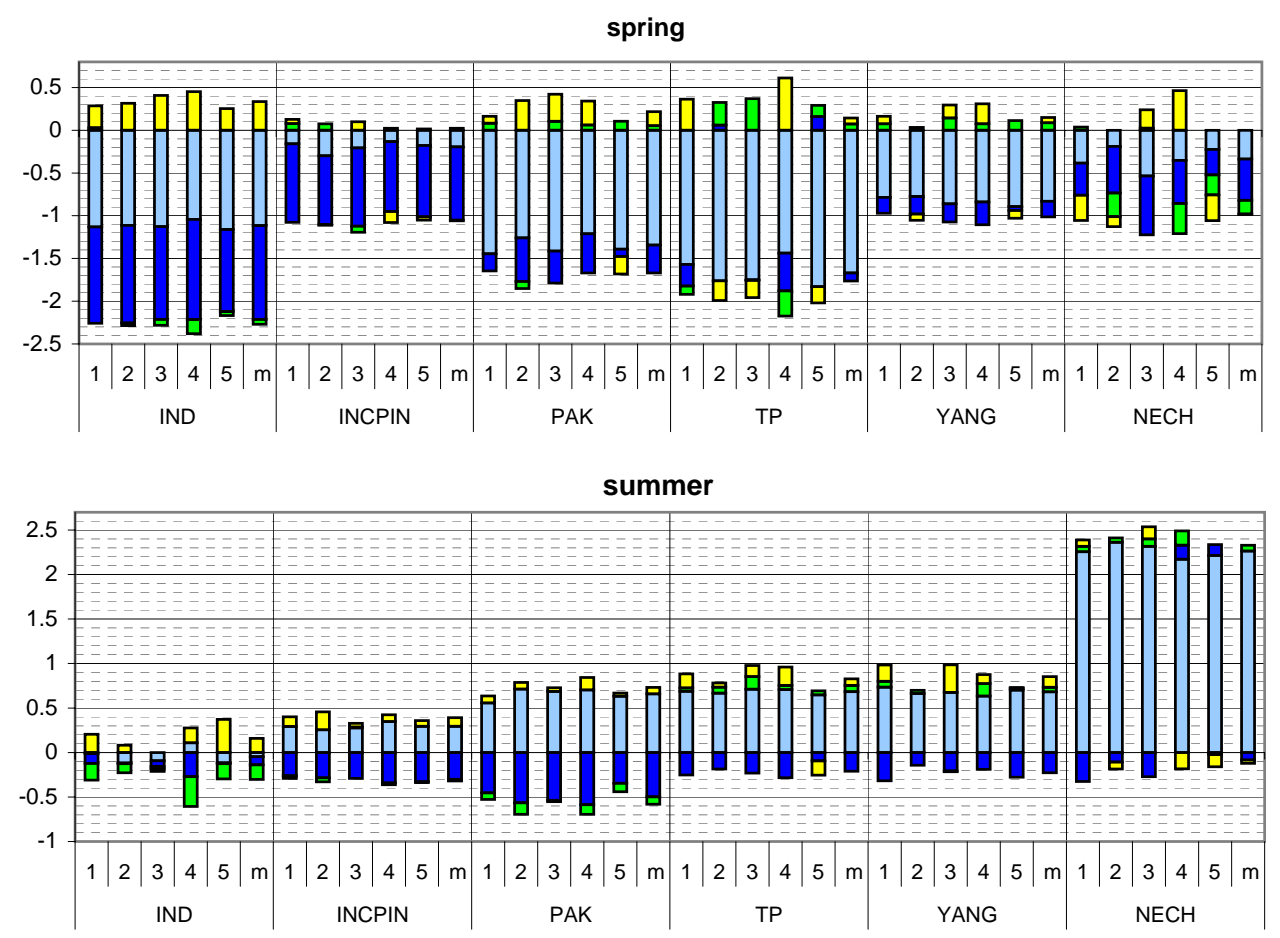

autumn

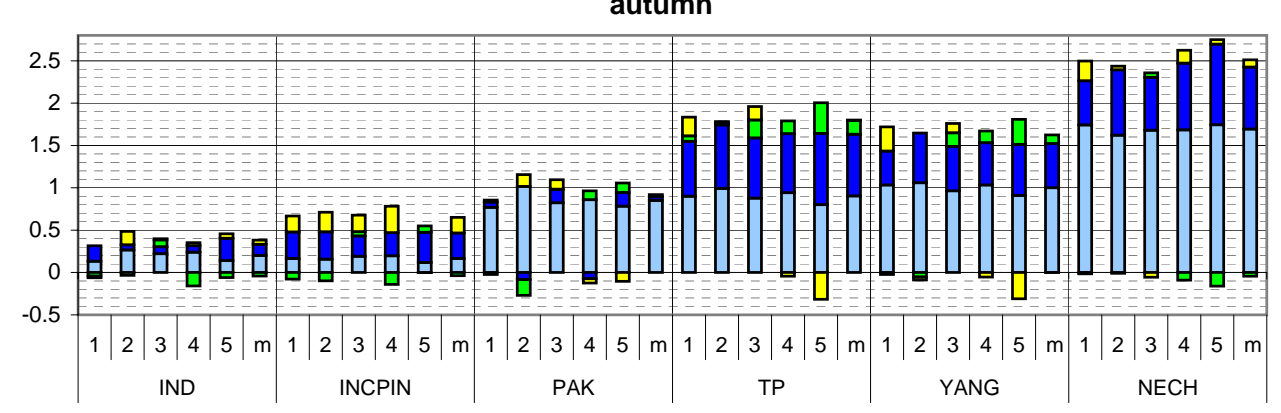

winter

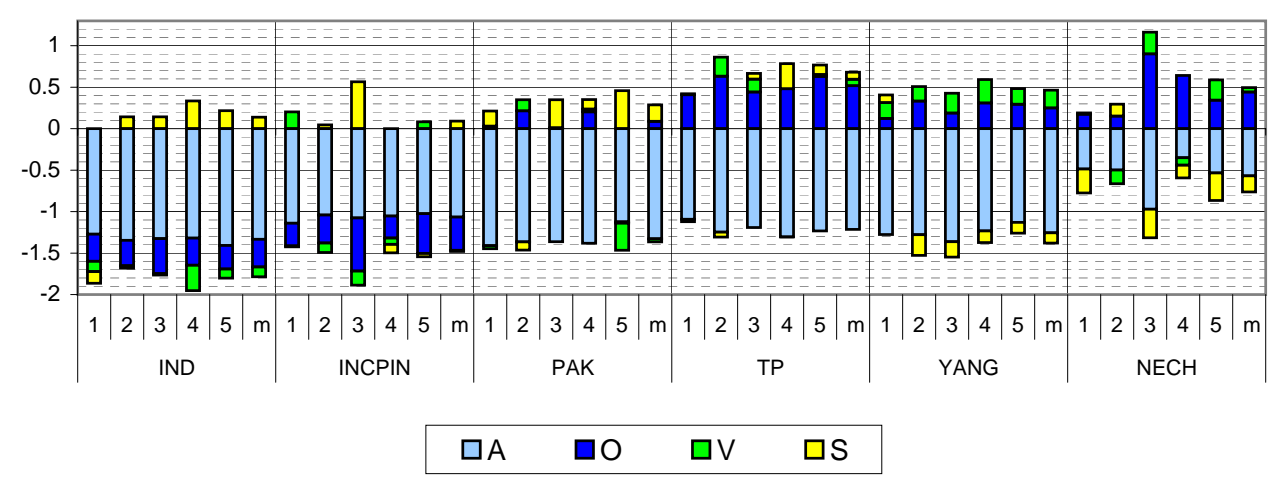

Fig. A1. Factors contributing to the seasonal temperature change $[K]$ between mid-Holocene $(6 \mathrm{k})$ and present-day $(0 \mathrm{k})$ climate for six regions in the area of the Asian monsoon. Depicted are seasonal averages for all 120-year periods as well as the 600-year mean. Light blue colours show the results of the atmosphere-only run, i.e. the direct response of atmospheric dynamics (A) to changes in insolation. Dark blue colours represent the contribution of ocean-atmosphere-interaction $(\mathrm{O})$, including sea-ice dynamics. Green colours indicate the contribution of vegetation-atmosphere interaction (V). Yellow colours reveal the contribution of the synergy (S) between atmosphere - ocean and atmosphere - vegetation interactions. Please note the change in scales. 


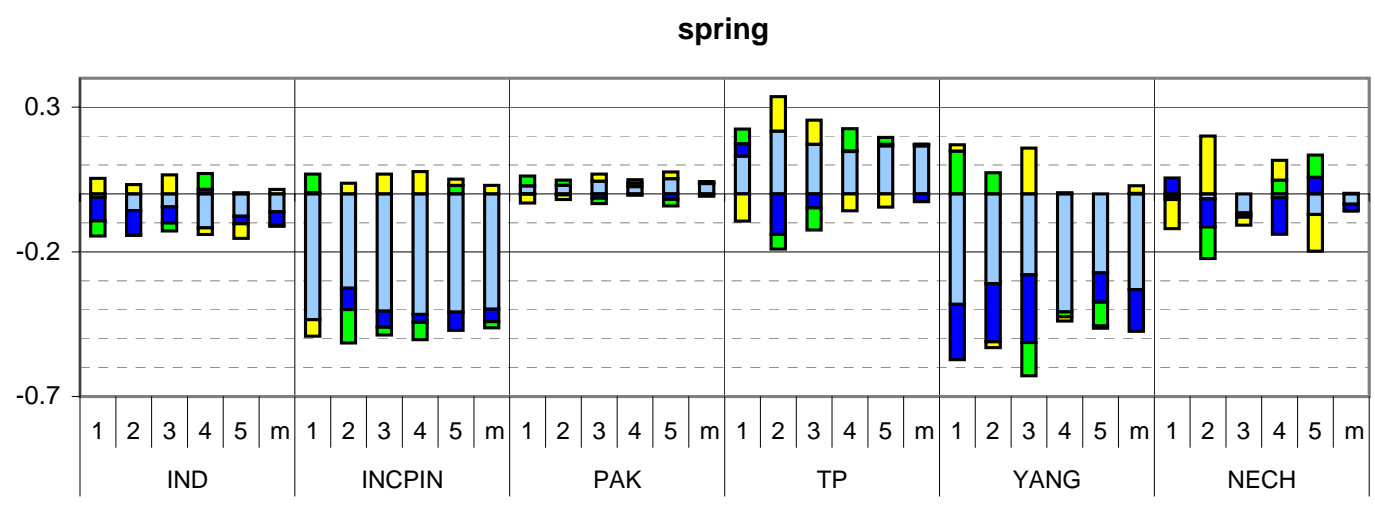

summer

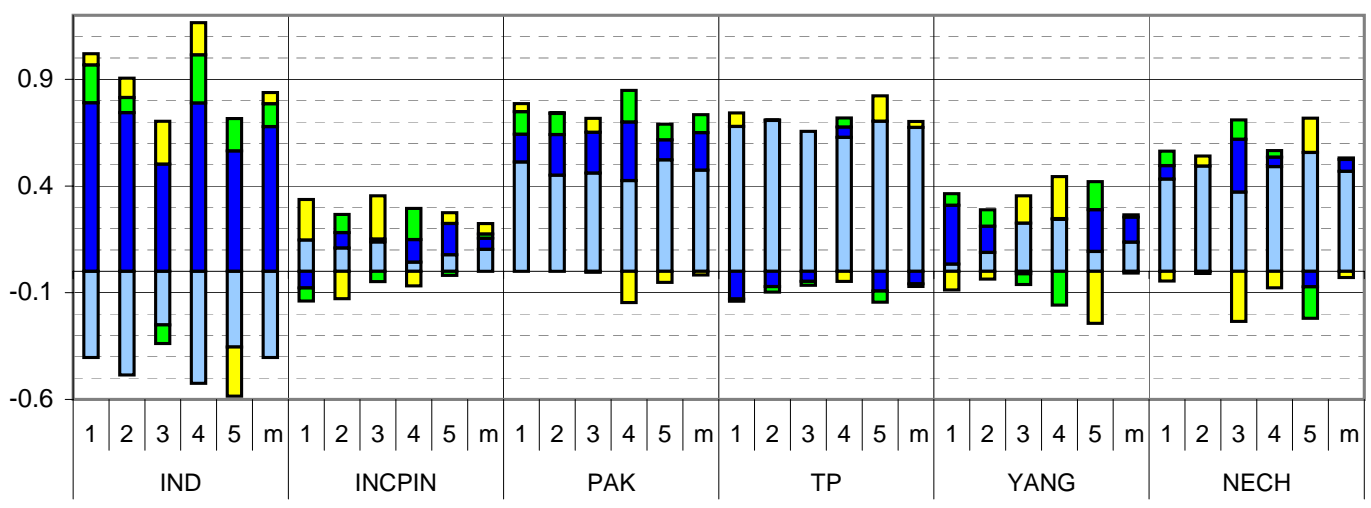

autumn

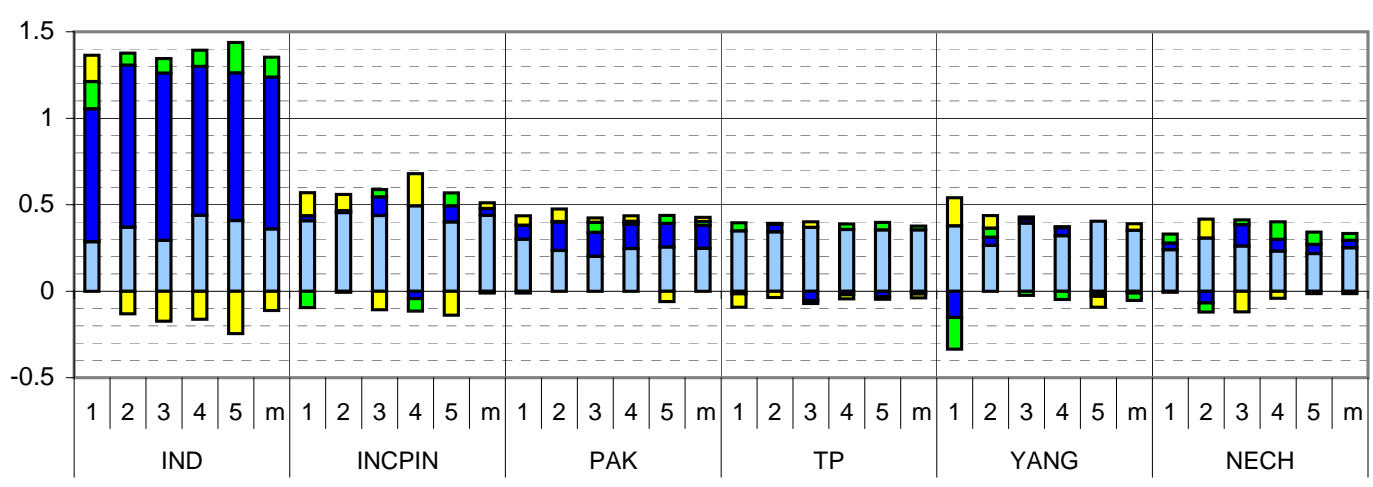

winter

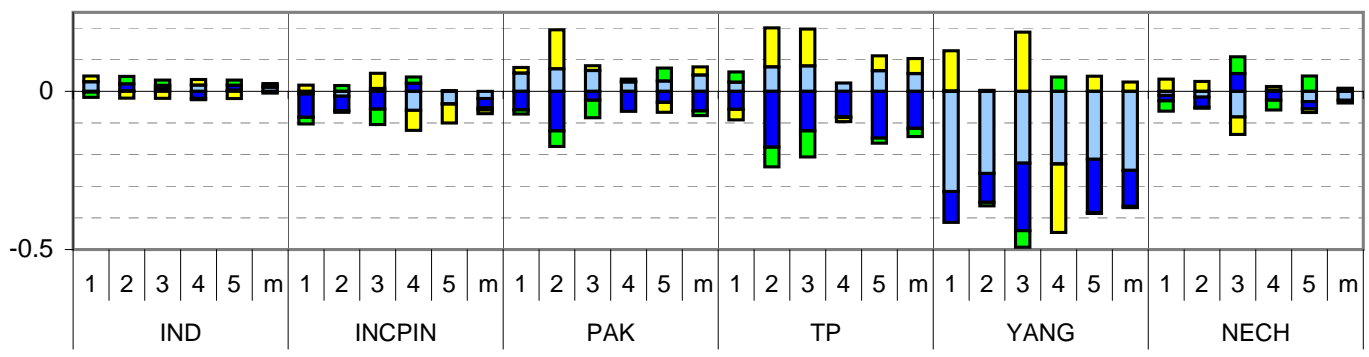

$\square A \square O \square \vee \square S$

Fig. A2. Same as A1, but for precipitation [mm/day]. Please note the different scales. 


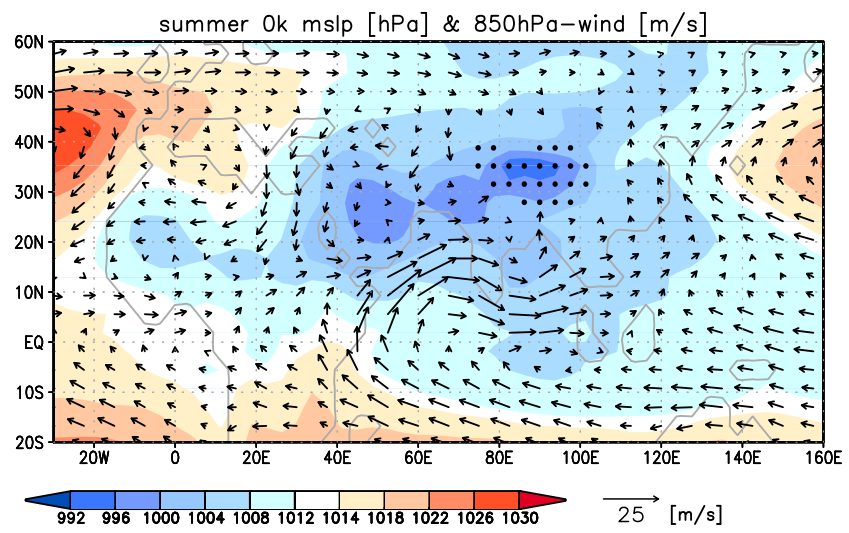

Fig. A3. Summer mean sea level pressure (shaded, [hPa]) and wind in $850 \mathrm{hPa}$ (vector, [m/s]) as simulated by the atmosphere-only run for present-day orbital conditions.

Acknowledgements. The authors want to thank Andrej Ganopolski, Potsdam-Institute for Climate Impact Research, Germany, Oliver Timm, IPRC, University of Hawaii, and an anonymous reviewer for constructive comments, which helped to improve the manuscript. AD was funded by the HOLOCV-project of the Priority Programme INTERDYNAMIK of the German Research Foundation (DFG). JO was funded by the International Max Planck Research School on Earth System Modelling. This study also contributes to the Cluster of Excellence CliSAP (Integrated Climate System Analysis and Prediction) funded by the German Federal Government and the German States.

The service charges for this open access publication have been covered by the Max Planck Society.

Edited by: V. Rath

\section{References}

An, Z., Porter, S. C., Kutzbach, J. E., Wu, X., Wang, S., Liu, X., Li, X., and Zhou, W.: Asynchronous Holocene optimum of the East Asian monsoon, Quat. Sci. Rev., 19, 743-762, 2000.

Berger, A.: Long-term variations of daily insolation and Quaternary climate changes, J. Atmos. Sci., 35, 12, 2362-2367, 1978.

Braconnot, P., Marti, O., Joussaume, S., and Leclainche, Y.: Ocean feedback in response to $6 \mathrm{kyr} \mathrm{BP}$ insolation, J. Climate, 13, 1537-1553, 2000.

Braconnot, P., Otto-Bliesner, B., Harrison, S., Joussaume, S., Peterchmitt, J.-Y., Abe-Ouchi, A., Crucifix, M., Driesschaert, E., Fichefet, Th., Hewitt, C. D., Kageyama, M., Kitoh, A., Laîné, A., Loutre, M.-F., Marti, O., Merkel, U., Ramstein, G., Valdes, P., Weber, S. L., Yu, Y., and Zhao, Y.: Results of PMIP2 coupled simulations of the Mid-Holocene and Last Glacial Maximum - Part 1: experiments and large-scale features, Clim. Past, 3, 261-277, 2007,

http://www.clim-past.net/3/261/2007/.

Braconnot, P., Otto-Bliesner, B., Harrison, S., Joussaume, S., Peterchmitt, J.-Y., Abe-Ouchi, A., Crucifix, M., Driesschaert, E.,
Fichefet, Th., Hewitt, C. D., Kageyama, M., Kitoh, A., Loutre, M.-F., Marti, O., Merkel, U., Ramstein, G., Valdes, P., Weber, L., Yu, Y., and Zhao, Y.: Results of PMIP2 coupled simulations of the Mid-Holocene and Last Glacial Maximum Part 2: feedbacks with emphasis on the location of the ITCZ and mid- and high latitudes heat budget, Clim. Past, 3, 279-296, 2007, http://www.clim-past.net/3/279/2007/.

Broström, A., Coe, M., Harrison, S. P., Gallimore, R., Kutzbach, J. E., Foley, J. A., Prentice, I. C., and Behling, P.: Land surface feedbacks and palaeomonsoons in northern Africa, Geophys. Res. Lett., 25, 19, 3615-3618, 1998.

Brovkin, V., Raddatz, T., Reick, C.H., Claussen, M., and Gayler, V.: Global biogeophysical interactions between forest and climate, Geophys. Res. Lett., 36, L07405, doi:10.1029/2009GL037543, 2009.

Claussen, M.: Modelling bio-geophysical feedback in the African and Indian monsoon region, Clim. Dyn., 13, 247-257, 1997.

Claussen, M. and Gayler, V.: The greening of Sahara during the mid-Holocene: Results of an interactive atmosphere - biome model, Global. Ecol. Biogeogr., 6, 369-377, 1997.

Clift, P. D. and Plumb, R. A.: The Asian monsoon: causes, history and effects, Cambridge Univ. Press, Cambridge, 270 pp., 2008.

Cui, X., Graf, H. F., Langmann, B., Chen, W., and Huang, R.: Climate impacts of anthropogenic land use changes on the Tibetan Plateau, Global Planet. Change, 54, 33-56, 2006.

Diffenbaugh, N. S. and Sloan, L. C.: Global climate sensitivity to land surface change: The mid Holocene revisited, Geophys. Res. Lett., 29(10), 1476, 114-1-114-4, doi:10.1029/2002GL014880, 2002

Ge, Q., Wang, S., Wen, Y., Shen, C., and Hao, Z.: Temperature and precipitation changes in China during the Holocene, Adv. Atmos. Sci., 24, 6, 1024-1036, 2007.

Hales, K., Neelin, J. D., and Zeng, N.: Interaction of Vegetation and Atmospheric dynamical mechanisms in the mid-Holocene African monsoon, J. Climate, 19, 4105-4120, 2006.

Harrison, S. P., Jolly, D., Laarif, F., Abe-Ouchi, A., Dong, B., Herterich, K., Hewitt, C., Joussaume, S., Kutzbach, J.E., Mitchel, J., De Noblet, N., and Valdes, P.: Intercomparison of simulated global vegetation distributions in response to $6 \mathrm{kyr} \mathrm{BP}$ orbital forcing, J. Climate, 11, 2721-2742, 1998.

He, J., Ju, J., Wen, Z., Lü, J., and Jin, Q.: A review of recent advances in Research on Asian monsoon in China, Adv. Atmos. Sci., 24, 6, 972-992, 2007.

Herzschuh, U., Winter, K., Wünnemann, B., and Li, S.: A general cooling trend on the central Tibetan Plateau throughout the Holocene recorded by the Lake Zigetang pollen spectra, Quat. Int., 154-155, 113-121, 2006.

Herzschuh, U., Kramer, A., Mischke, S., and Zhang, C.: Quantitative climate and vegetation trends since the late glacial on the northeastern Tibetan Plateau deduced from Koucha Lake pollen spectra, Quat. Res., 71, 162-171, 2009.

Hewitt, C. D. and Mitchell, J. F. B.: A fully-coupled GCM simulation of the climate of the mid-Holocene, Geophys. Res. Lett., 25, 361-364, 1998.

Irizarry-Ortiz, M., Wang, G., and Elthair, E. A. B.: Role of the biosphere in the mid-Holocene climate of West Africa, J. Geophys. Res., 108(D2), doi:10.1029/2001JD000989, 2003

Jolly, D., Prentice, I. C., Bonnefille, R., Ballouche, A., Bengo, M., 
Brenac, P., Buchet, G., Burney, D., Cazet, J.P., Cheddadi, R., Edorh, T., Elenga, H., Elmoutaki, S., Guiot, J., Laarif, F., Lamb, H., Lezine, A.M., Maley, J., Mbenza, M., Peyron, O., Reille, M., Reynaud-Farrera, I., Riollet, G., Ritchie, J.C., Roche, E., Scott, L., Ssemmanda, I., Straka, H., Umer, M., Van Campo, E., Vilimumbalo, S., Vincens, A., and Waller, M.: Biome reconstruction from pollen and plant macrofossil data for Africa and the Arabian peninsula at 0 and 6000 years, J. Biogeogr., 25, 6, 1007-1027, 1998.

Joussaume, S. and Braconnot, P.: Sensitivity of paleoclimate simulations results to season definitions, J. Geophys. Res., 102(D2), 1943-1956, 1997.

Joussaume, S., Taylor, K. E., Braconnot, P., Mitchell, J. F. B., Kutzbach, J. E., Harrison, S. P., Prentice, I. C., Broccoli, A.J., Abe-Ouchi, A., Bartlein, P. J., Bonfiels, C., Dong., B., Guiot, J., Herterich, K., Hewit, C. D., Jolly, D., Kim, J. W., Kislov, A., Kitoh, A., Loutre, M. F., Masson, V., McAvaney, B., McFarlane, N., deNoblet, N., Peltier, W. R., Peterschmitt, J. Y., Pollard, D., Rind, D., Royer, J. F., Schlesinger, M. E., Syktus, J., Thompson, S., Valdes, P., Vettoretti, G., Webb, R. S., and Wyputta, U.: Monsoon changes for 6000 years ago: Results of 18 simulations from the Paleoclimate Modeling Intercomparison Project (PMIP), Geophys. Res. Lett., 26(7), 859-862, 1999.

Jungclaus, J. H., Botzet, M., Haak, H., Keenlyside, N., Luo, J.-J., Latif, M., Marotzke, J., Mikolajewicz, U., and Roeckner, E.: Ocean circulation and tropical variability in the coupled model ECHAM5/MPI-OM, J. Climate, 19, 3952-3972, 2006.

Kohfeld, K. E. and Harrison, S. P.: How well can we simulate past climates? Evaluating the models using global palaeo-environmental data sets, Quat. Sci. Rev., 19, 321-346, 2000.

Kutzbach, J. E. and Otto-Bliesner, B.: The sensitivity of the African-Asian monsoonal climate to orbital parameter changes for $9000 \mathrm{yr}$ BP in a low-resolution general circulation model, J. Atmos. Sci., 39, 1177-1188, 1982.

Kutzbach, J. E. and Liu, Z.: Oceanic feedback on the western African monsoon at $6000 \mathrm{BP}$, Science, 278, 440-443, 1997.

Lau, K.-M., Kim, K.-M., and Yang, S.: Dynamical and boundary forcing characteristics of regional components of the Asian summer monsoon, J. Climate, 13, 2461-2482, 2000.

Levis, S., Bonan, G.B., and Bonfils, C.: Soil feedback drives the mid-Holocene North African monsoon northward in fully coupled CCSM2 simulations with a dynamic vegetation model, Clim. Dyn., 23, 791-802, 2004.

Li, Y. and Harrison, S.: Simulations of the impact of orbital forcing and ocean on the Asian summer monsoon during the Holocene, Global Planet. Change, 60, 505-522, 2008.

Li, Y., Harrison, S., Zhao, P., and Ju, J.: Simulations of the impact of dynamic vegetation on interannual and interdecadal variability of Asian summer monsoon with modern and mid-Holocene orbital forcings, Global Planet. Change, 66, 3/4, 235-252, 2009.

Liu, Y., Qing, B., Duan, A., Qian, Z., and Wu., G.: Recent progress in the impact of the Tibetan Plateau on climate in China, Adv. Atmos. Sci., 24, 6, 1060-1076, 2007.

Liu, Z., Harrison, S. P., Kutzbach, J. E., and Otto-Bliesner, B.: Global monsoons in the mid-Holocene and oceanic feedback, Clim. Dyn., 22, 157-182, 2004.

Maher, B. A.: Holocene variability of the East Asian summer monsoon from Chinese cave records: a re-assessment, The
Holocene, 18, 6, 861-866, 2008.

Marzin, C. and Braconnot, P.: Variations of Indian and African monsoons induced by insolation changes at 6 and $9.5 \mathrm{kyr} \mathrm{BP}$, Clim. Dyn. 33(2-3), 215, 2009a.

Marzin, C. and Braconnot, P.: The role of the ocean feedback on Asian and African monsoon variations at $6 \mathrm{kyr}$ and $9.5 \mathrm{kyr} \mathrm{BP}, \mathrm{C}$. R. Geosci., 341, 8-9, 643-655, 2009b.

Ohgaito, R. and Abe-Ouchi, A.: The role of ocean thermodynamics and dynamics in Asian summer monsoon changes during the mid-Holocene, Clim. Dyn., 29, 39-50, 2007.

Otto, J., Raddatz, T., Claussen, M., Brovkin, V., and Gayler, V. : Separation of atmosphere-ocean-vegetation feedbacks and synergies for mid-Holocene climate, Geophys. Res. Lett., 36, 9, doi:10.1029/2009GL037482, 2009a.

Otto, J., Raddatz, T., and Claussen, M.: Climate variability-induced uncertainty in mid-Holocene atmosphere-ocean-vegetation feedbacks, Geophys. Res. Lett., 36, 23, doi:10.1029/2009GL041457, 2009b.

Raddatz, T. J., Reick, C. H., Knorr, W., Kattge, J., Roeckner, E., Schnur, R., Schnitzler, K.-G., Wetzel, P., and Jungclaus, J.: Will the tropical land biosphere dominate the climate-carbon cycle feedback during the twenty-first century? Clim. Dyn., 29, 565-574, 2007.

Ren, G.: Changes in forest cover in China during the Holocene, Veget. Hist. Archaeobot., 16, 119-126, 2007.

Ren, G. and Beug, H.-J.: Mapping Holocene pollen data and vegetation of China. Quat. Sci. Rev., 21, 1395-1422, 2002.

Roeckner, E., Bäuml, G., Bonaventura, L., Brokopf, R., Esch, M., Giorgetta, M., Hagemann, S., Kirchner, I., Kornblueh, L., Manzini, E., Rhodin, A., Schlese, U., Schultzweida, U., and Tompkins, A.: The atmospheric general circulation model ECHAM5. Part I: Model description. MaxPlanckInst. f. Meteor., Report No. 349, Hamburg, Germany, 2003.

Roeckner, E., Brokopf, R., Esch, M., Giorgetta, M., Hagemann, S., Kornblueh, L., Manzini, E., Schlese, U., and Schulzweida, U.: Sensitivity of simulated climate to horizontal and vertical resolution in the ECHAM5 atmosphere model, J. Climate, 19, 3771-3791, 2006.

Shen, J., Jones, R. T., and Yang, X.: The Holocene vegetation history of Lake Erhai, Yunnan province, southwestern China: the role of climate and human forcings, The Holocene, 16, 265-276, 2006.

Stein, U. and Alpert, P.: Factor separation in numerical simulations, J. Atmos. Sci., 50, 2107-2115, 1993.

Tang, L., Shen, C., Liu, K., and Overpeck, J.T.: New high resolution pollen records from two lakes in Xizang (Tibet), Acta Bot. Sin., 41, 896-902, 1999.

Texier, D., de Noblet, N., and Braconnot, P.: Sensitivity of the African and Asian monsoons to mid-Holocene insolation and data-inferred surface changes, J. Climate, 13, 164-181, 2000.

Voss, R. and Mikolajewicz, U.: The climate of 6000 years BP in near-equilibrium simulations with a coupled AOGCM, Geophy. Res. Lett., 28, 11, 2213-2216, 2001.

Wang, H.-J.: Role of vegetation and soil in the Holocene megathermal climate over China, J. Geophys. Res., 104, D8, 9361-9367, 1999.

Webster, P. J., Magaòa, V. O., Palmer, T. N., Shukla, J., Tomas, R. A., Yanai, M., and Yasunari, T.: Monsoons: Processes, predictability, and the prospects for prediction, J. Geophys. Res., 
103(C7), 14451-14510, 1998.

Wei, J. and Wang, H.: A possible role of solar radiation and ocean in the mid-Holocene East Asian monsoon Climate Adv. Atmos. Sci., 21, 1, 1-12, 2004.

Winkler, M. G. and Wang, P. K.: The late-Quaternary vegetation and climate of China, in: Global Climate since the Last Glacial Maximum, edited by: Wright, H. E., Kutzbach, J. E., Webb III, T., Ruddiman, W. F., Street-Perrott, F. A., Bartlein, P. J., University of Minnesota Press, Minneapolis, 221-264, 1993.

Wu, G., Liu, Y., Wang, T, Wan, R., Liu, X., Li, W., Wang, Z., Zhang, Q., Duan, A., and Liang, X.: The influence of mechanical and thermal forcing by the Tibetan Plateau on Asian climate, J. Hydrometeorol., 8, 770-789, 2007.

Yasunari, T., Saito, K., and Takata, K.: Relative roles of large-scale orography and land surface processes in the global hydroclimate. Part 1: Impacts on monsoon systems and the Tropics, J. Hydrometeorol., 7, 626-641, 2006.
Yu, G., Chen, X., Ni, J., Cheddadi, R., Guiot, J., Han, H., Harrison, S., Huang, C., Ke, M., Kong, Z., Li, S., Li, W., Liew, P., Liu, G., Liu, J., Liu, Q., Liu, K.-B., Prentice, I.C., Ren, G., and Qui, W.: Palaeovegetation of China: a pollen data-based synthesis for the mid-Holocene and last glacial maximum, J. Biogeogr, 27, 635-664, 2000.

Zhao, Y., Yu, Z., and Chen, F.: Spatial and temporal patterns of Holocene vegetation and climate changes in arid and semi-arid China, Quat. Int., 194, 6-18, 2009.

Zheng, Y. Q., Yu, G., Wang, S. M., Xue, B., Zhuo, D. Q., Zeng, X. M., Liu, H. Q.: Simulation of paleoclimate over East Asia at $6 \mathrm{ka} \mathrm{BP}$ and $21 \mathrm{ka} \mathrm{BP}$ by regional climate model, Clim. Dyn., 23, 513-529, 2004. 